\title{
Insights into Doxorubicin-induced Cardiotoxicity: Molecular Mechanisms, Preventive Strategies, and Early Monitoring
}

\author{
Nadine Wenningmann, Merle Knapp, Anusha Ande, Tanaya R. Vaidya, and \\ Sihem Ait-Oudhia \\ Center for Pharmacometrics and Systems Pharmacology, Department of Pharmaceutics, College of Pharmacy, University of \\ Florida, Orlando, Florida
}

Received January 7, 2019; accepted June 3, 2019

\section{ABSTRACT}

Doxorubicin (DOX) is one of the most effective anticancer drugs to treat various forms of cancers; however, its therapeutic utility is severely limited by its associated cardiotoxicity. Despite the enormous amount of research conducted in this area, the exact molecular mechanisms underlying DOX toxic effects on the heart are still an area that warrants further investigations. In this study, we reviewed literature to gather the best-known molecular pathways related to DOX-induced cardiotoxicity (DIC). They include mechanisms dependent on mitochondrial dysfunction such as DOX influence on the mitochondrial electron transport chain, redox cycling, oxidative stress, calcium dysregulation, and apoptosis pathways. Furthermore, we discuss the existing strategies to prevent and/or alleviate DIC along with various techniques available for therapeutic drug monitoring (TDM) in cancer patients treated with DOX. Finally, we propose a stepwise flowchart for TDM of DOX and present our perspective at curtailing this deleterious side effect of DOX.

\section{Introduction}

Anthracyclines are widely recognized as a class of effective chemotherapeutic agents to treat different types of cancer since their discovery in the 1960s (Kayser et al., 1999; Matsuoka et al., 2000; Shah, 2009; Octavia et al., 2012; Pendlebury et al., 2017; Qiu et al., 2017; Wei et al., 2017). Doxorubicin (DOX), a product of Streptomyces peucetius var. caesius, is a prototype agent of anthracycline antibiotics (Blum and Carter, 1974). It is proven efficacious against a wide range of human malignant neoplasms, including a variety of solid tumors, breast cancer, Hodgkin's disease, Kaposi's sarcoma, acute lymphoblastic leukemia, pediatric leukemia, lung cancer, lymphomas, and several metastatic cancers (Vejpongsa and Yeh, 2014). Despite its widespread use, DOX therapy demonstrated dose-limiting effects owing to its acute and chronic cardiac toxicity (Gao et al., 2016). Based on small

This work was partially supported by the University of Florida College of Pharmacy PROSPER Excellence Award (to S.A.-O.)

https://doi.org/10.1124/mol.119.115725. retrospective studies in childhood cancer survivors previously treated with anthracyclines, the cardiotoxicity of anthracyclines can be classified in three categories based on the time of onset. First is the acute cardiotoxicity, which occurs after a single course of chemotherapy, and where clinical manifestations appear within 2 weeks from the end of treatment. Second is the early-onset chronic cardiotoxicity, which develops within 1 year post-treatment cessation, and usually manifests itself as a dilated and hypokinetic cardiomyopathy leading to heart failure (HF). Third is the late-onset chronic cardiotoxicity, which develops years or even decades after the end of chemotherapy (Cardinale et al., 2015). However, it is worth mentioning that this classification is inappropriate for adult populations because no prospective study has reported regular monitoring of cardiac function in adult patients for more than 3 years. Alternately, based on the stage of disease progression and the clinical manifestations, HF symptoms that are diagnosed several years after anthracycline therapy can be defined as late. The left ventricular (LV) ejection fraction (LVEF) reduction that occurs within months post-treatment

ABBREVIATIONS: ACE, adrenocortical extract; AIF, apoptosis-inducing factor; BNP, brain natriuretic peptide; CHF, congestive HF; cTnT, cardiac troponin T; DIC, DOX-induced cardiotoxicity; DOX, doxorubicin; DR, death receptor; EPO, erythropoietin; ERK, extracellular signal-regulated kinase; ET-1, endothelin 1; ETC, electron transport chain; FDA, Food and Drug Administration; HF, heart failure; HPLC, high-performance liquid chromatography; ${ }^{123}$ I-MIBG, 123-labeled metaiodobenzylguanidine; In-111, Indium-111; LC-MS/MS, liquid chromatography mass spectroscopycoupled mass spectroscopy; LV, left ventricle; LVEF, LV ejection fraction; mtDNA, mitochondrial DNA; NF $\kappa$ B, nuclear factor- $\kappa$ B; PEG, polyethylene glycol; ROS, reactive oxygen species; SERCA, sarco/endoplasmic reticulum $\mathrm{Ca}^{2+}$ ATPase; SR, sarcoplasmic reticulum; TDM, therapeutic drug monitoring; TPO, thrombopoietin; TRAIL, tumor necrosis factor-related apoptosis inducing ligand; TUNEL, terminal deoxynucleotidyl transferasemediated digoxigenin-deoxyuridine nick-end labeling. 
with anthracyclines can be defined as early, whereas myocardial damage using a biomarker like troponin can be identified during or soon after therapy, and is termed as acute (Cardinale et al., 2015).

A cumulative treatment dose of $>350 \mathrm{mg} / \mathrm{m}^{2}$ free DOX shows a dose-dependent decrease in the LVEF, and, at a cumulative dose of $550 \mathrm{mg} / \mathrm{m}^{2}$, a sharp increase in the prevalence of HF is reported (O'Brien et al., 2004; Volkova and Russell, 2011). It is reported that the percentage of patients with DOX-related congestive $\mathrm{HF}(\mathrm{CHF})$ increases with an increase in the patients' cumulative dose of DOX therapy. For example, $5 \%$ of patients manifest CHF at a cumulative dose of $400 \mathrm{mg} / \mathrm{m}^{2}$, which increases to $16 \%$ at a dose of $500 \mathrm{mg} / \mathrm{m}^{2}, 26 \%$ at a dose of $550 \mathrm{mg} / \mathrm{m}^{2}$, and about $48 \%$ at doses above $700 \mathrm{mg} / \mathrm{m}^{2}$. The toxicity caused by DOX further increases while administered in combination with other targeted agents such as trastuzumab, an anti-epidermal growth factor receptor 2 monoclonal antibody, hence remaining a major contributor to chemotherapyinduced heart diseases (Conte et al., 2001; Rochette et al., 2015; Mitry and Edwards, 2016). Although DOX-induced acute cardiotoxicity emerges during or immediately after treatment and typically involves reversible hypotension, pericarditis and transient electrocardiographic abnormalities such as nonspecific changes in the ST-T waves on an ECG, QT prolongation, and vasodilatation (Licata et al., 2000), its chronic cardiotoxicity develops after completion of cumulative dose regimens and results in irreversible cardiomyopathy, steadily progressing toward CHF (Licata et al., 2000; Takemura and Fujiwara, 2007).
The precise molecular mechanisms by which DOX induces cardiac dysfunction are still not completely elucidated. Due to the existence of various and interconnected intracellular signaling pathways triggered by DOX, in this review, we limit our discussion to highlight the essential molecular mechanisms of DOX-induced cardiotoxicity (DIC) involving potential pharmacological targets for therapeutic interventions. Our review also focuses on presenting various preventive strategies to lower, and ideally, to overcome cardiotoxicity, and narrate the procedure of therapeutic drug monitoring presently followed in clinical settings.

\section{Molecular Mechanisms of DIC}

DOX acts by multiple mechanisms of action. Currently it is unclear which of these mechanisms are the most responsible for its associated cardiac toxicity. Many articles support the view that the generation of reactive oxygen species (ROS) upon DOX treatment and its consequential lipid peroxidation, calcium dysregulation, and intervention in energy transfer could cause HF (Tokarska-Schlattner et al., 2006; Takemura and Fujiwara, 2007; Renu et al., 2018). However, the underlying biochemical mechanisms of its toxicity are still not fully elucidated. In the following section, we present the most probable intracellular/signaling mechanisms behind cardiotoxicity, as summarized in Fig. 1.

Generation of ROS. One of the major mechanisms of DIC is strongly linked to mitochondrial dysfunction, leading to an increased generation of intracellular ROS and oxidative

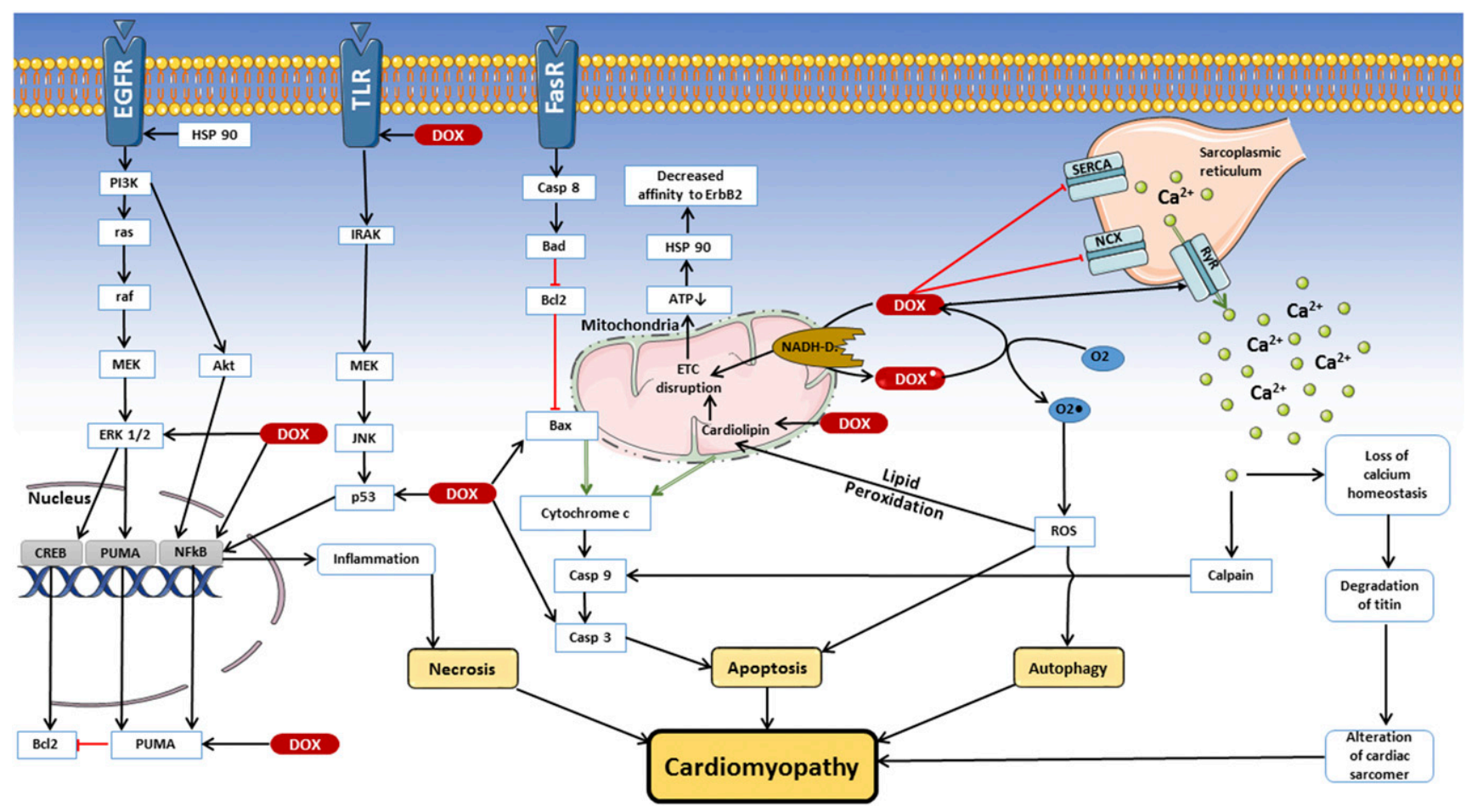

Fig. 1. Intracellular signaling pathways altered by DOX action on cardiomyocytes. Figure depicts molecular mechanisms of DOX-mediated cardiomyopathy due to necrosis, apoptosis, and autophagy. Akt, AKT8 virus oncogene cellular homolog; Bad, Bcl-2-associated death promoter; Bax, bcl-2-like protein 4; Bcl-2, B-cell lymphoma 2; Casp, caspase; CREB, cAMP response element-binding protein; EGFR, epidermal growth factor receptor; FasR, Fas cell surface death receptor; Hsp 90, heat shock protein 90; IRAK, interleukin-1 receptor-associated kinase; JNK, c-Jun N-terminal kinases; MEK, mitogen-activated protein kinase; NADH-D, NADH dehydrogenase; NCX, sodium-calcium exchanger; PI3K, phosphatidylinositol 3-kinase; PUMA, p53 upregulated modulator of apoptosis; Raf, rapidly accelerated fibrosarcoma; Ras, Rat sarcoma; RyR, ryanodine receptor; TLR, Toll-like receptors. 
stress. Mitochondria are the most injured intracellular organelles upon cell exposure to DOX. One of the contributing factors for the accumulation of DOX in the inner mitochondrial membrane is its high-affinity binding to cardiolipin (Goormaghtigh et al., 1986, 1990). Cardiolipin is a phospholipid present in the inner leaflet of the mitochondrial membrane and is known for maintaining mitochondrial structure, function, cardiac energy metabolism, and cell survival (Schlame et al., 2000). Mitochondrial toxicity arising from the cardiolipinbound DOX is majorly mediated through oxidative stress (Minotti et al., 2004). Electrostatic binding between cardiolipin and DOX leads to disruption of the activity of complexes I, III, and IV in the electron transport chain (ETC), all of which are known to require cardiolipin to maintain maximal activity. In addition, it has been shown that complex I can catalyze reduction of DOX to a semiquinone radical species. These species can be reoxidized by transfer of an electron to molecular oxygen $\left(\mathrm{O}_{2}\right)$, leading to the formation of superoxide anion. This transfer of electrons through DOX can result in the formation of an even stronger bond with cardiolipin, leading to further disruption of the ETC (Goormaghtigh et al., 1983; Marcillat et al., 1989). Owing to its chemical structure that consists of a tetracycline moiety containing a quinone, DOX can also be easily reduced into semiquinone by endothelial nitric oxide synthase (Delemasure et al., 2006). Different mitochondrial and membrane-bound enzymes can catalyze the conversion of quinone to the semiquinone state, as described earlier. Few flavoprotein oxidoreductases that catalyze the redox quinone cycle of DOX include NADH dehydrogenase (complex I of the ETC), NADPH/cytochrome P450, localized at the endoplasmic reticulum, and xanthine oxidase (Delemasure et al., 2006; Takemura and Fujiwara, 2007). The semiquinone can easily auto-oxidize by transferring an electron to molecular oxygen $\left(\mathrm{O}_{2}\right)$, converting back to the parent compound, which is available for a new redox cycle, during which superoxide radicals are produced (Delemasure et al., 2006). Of the superoxide radicals, hydrogen peroxide $\left(\mathrm{H}_{2} \mathrm{O}_{2}\right)$ can be formed by manganese superoxide dismutase, which can be further converted into more reactive hydroxyl radicals in the presence of iron or copper (Delemasure et al., 2006).

DOX accumulation in mitochondria leads to enhanced production of ROS and reactive nitrogen species as well (Weinstein et al., 2000; Priya et al., 2017). These reactive species in turn cause peroxidation of lipids and oxidative damage to DNA and proteins, resulting in mitochondrial DNA (mtDNA) damage, loss of ATP levels, peroxidation of cardiolipin, and mitochondrial permeability transition (Mizutani et al., 2005; Tokarska-Schlattner et al., 2006). A close interaction between ROS, mtDNA damage, and the ETC can result in the formation of a vicious loop in two ways: enhanced ROS levels can directly inactivate the ETC and result in further ROS formation (de Oliveira and Niederer, 2016). Alternatively, mtDNA damage caused by increased ROS levels can inhibit ETC proteins aggravating mitochondrial dysfunction and ROS formation (de Oliveira and Niederer, 2016). Altogether, this cycle of events results in the release of cytochrome $c$ as well as the release of additional apoptogenic factors from mitochondria, hence initiating the apoptotic pathway. Because mitochondria are abundantly present in the energy-demanding cardiac tissue-20\%-40\% of its cellular volume - the production of free radicals through oxidative metabolism in cardiomyocytes upon exposure to DOX is likely high, hence making the heart a highly susceptible tissue to DOX-mediated oxidative damage.

Apoptotic Pathway. DOX activates apoptosis by both intrinsic and extrinsic pathways (Nakamura et al., 2000; Priya et al., 2017; Zhao and Zhang, 2017). Mizutani et al. (2005) showed that human promyelocytic leukemia (HL-60) cells, treated with DOX, exhibited an activation of caspase- 3 protein, resulting in cell death. In their report, they identified a $\mathrm{H}_{2} \mathrm{O}_{2}$-dependent mechanism at mediating apoptosis through poly(ADP-ribose) polymerase, NADPH oxidase activation, and increased mitochondrial membrane permeability. Mitochondrial-dependent intrinsic pathway plays a key role in DIC. This pathway is activated by upregulation of proapoptotic proteins such as Bax, which promotes the release of cytochrome $c$ from mitochondria, leading to activation of caspase-9 that further causes the activation of effector caspase-3 (Liu et al., 2008b). An elegant study performed in rat cardiomyoblasts $(\mathrm{H} 9 \mathrm{c} 2)$ demonstrated the sequential events of molecular mechanisms, highlighting the importance of NADPH oxidase/ROS-mediated nuclear factor- $\kappa \mathrm{B}$ $(\mathrm{NF} \kappa \mathrm{B})$-signaling cascade at triggering DOX-mediated apoptosis. The extracellular signal-regulated kinases 1 and $2\left(\mathrm{ERK}_{1 / 2}\right)$ and mitogen-activated kinases are also involved in the above signaling cascade modulated by NADPH/ROS system, resulting in a NF- $\kappa \mathrm{B}$ activation and ultimately cell death. Another finding also reported the involvement of $\mathrm{ERK}_{1 / 2} / \mathrm{p} 53$ pathway and the activation of the $\mathrm{NF} \kappa \mathrm{B}$-dependent p53 upregulated modulator of apoptosis in DOX-induced cardiomyocyte apoptosis (Zhang et al., 2016). Similarly, the roles of ERKs and p53 at mediating DOXinduced apoptosis in H9c2 cells and cardiomyocytes are demonstrated in a study by Liu et al. (2008a).

Additionally, DOX is also shown to mediate cardiomyocyte apoptosis through extrinsic pathway mediators such as death receptors (DRs). Zhao and Zhang (2017) demonstrated the upregulation of DRs such as tumor necrosis factor-related apoptosis-inducing ligand (TRAIL), Fas, DR4, and DR5 in DOX-treated human-induced pluripotent stem cell-derived cardiomyocytes. These upregulated DRs bind to their cognate ligands and trigger the caspase cascade, ultimately leading to apoptosis. A TRAIL further augmented DIC, suggesting that serum levels of TRAIL could be used as a predictive biomarker to identify populations at higher risk for DIC (Zhao and Zhang, 2017). However, despite the involvement of caspase activation in mediating apoptosis, caspase inhibitors do not completely prevent cell death. This finding led to the identification of a caspase-independent pathway involving the role of mitochondrial apoptosis-inducing factor (AIF) (Moreira et al., 2014). In this finding, DOX-mediated ROS generation increased cathepsin B activity, which mediated AIF release from mitochondria following its interaction with Bax clusters. AIF caused large-scale DNA damage, an enhanced expression of $\mathrm{p} 53$, and the activation of poly(ADP-ribose) polymerase 1 , resulting in caspase-independent apoptosis.

In vivo, a study in DOX-treated male Wistar rats indicated that acute DIC involved cardiomyocyte apoptosis as assessed by the terminal deoxynucleotidyl transferase-mediated digoxigenindeoxyuridine nick-end labeling (TUNEL) assay in postmortem analyses of rat hearts (Arola et al., 2000). However, cumulative doses of DOX did not lead to an additive effect in the percentage of TUNEL-positive cardiomyocytes. Moreover, the percentage of apoptotic cells gradually declined to baseline levels, after 24-48 hours post-dosing with a single injection and at follow-up after cumulative dosing, suggesting cardiomyocyte apoptosis to be an 
acute cardiotoxic effect. In a clinical study, myocardial biopsies of childhood cancer patients demonstrated that DOX treatment may impair myocardial growth, as observed by the disproportionately small increase in left ventricular wall thickness in relation to somatic growth in patients. This was attributed to DOX-mediated loss or damage of a critical number of cardiac myocytes, resulting in numbers that were far lower than those required for the formation of normal adult myocardial mass (Lipshultz et al., 1991). Similar results were also observed in children with DOX-induced CHF (Goorin et al., 1990). In another clinical study, case reports of two adult patients demonstrated a striking decrease in the number of cardiac myocytes and a degeneration of the remaining myocardial cells in postmortem pathoclinical analyses. Both patients had received a cumulative dose of $>700 \mathrm{mg} / \mathrm{m}^{2}$, which was highly correlated with development of CHF (Lefrak et al., 1973). Taken together, these findings suggest cardiomyocyte apoptosis to be an important mechanism of cardiac toxicity, especially in children, leading to inadequate ventricular mass development and important cardiac complications in later years. In addition, preclinical and clinical evidence are indicative of cardiomyocyte apoptosis as both an acute and chronic side effect of DOX therapy.

Calcium Dysfunction. Calcium dysregulation is another well-known and established mechanism contributing to DOX cardiotoxicity (Wallace, 2007). Doxorubicinol, the hydroxyl metabolite of DOX, is known to affect calcium homeostasis by multiple mechanisms, including the modulation of the sarco/endoplasmic reticulum $\mathrm{Ca}^{2+}$ ATPase (SERCA) present on sarcoplasmic reticulum (SR) and the sodium/potassium exchanger on sarcolemma (Nicolay et al., 1986; Mitry and Edwards, 2016). Decreased gene expression levels of SR proteins responsible for calcium transport are found to be the underlying cause of altered calcium homeostasis, as observed in a rabbit model of cardiomyopathy following treatment with DOX (Arai et al., 1998). In addition, a comprehensive study examining the role of calcium imbalance at inducing apoptosis identified the role of calcineurin, a calcium-dependent phosphatase, at triggering apoptosis mediated through Fas (Kalivendi et al., 2005). The major findings from this study showed that mitochondrial ROS generated from the exposure of rat cardiac cells to DOX led to an increase in cytosolic calcium levels. The latter increase led to a calcineurin-dependent activation of the nuclear factor of activated T-lymphocytes, which further enhanced the Fasmediated cardiac cell death. Furthermore, experimental examinations of the calcium/calmodulin-dependent protein kinase revealed its role in disturbing calcium balance through promoting SR calcium leakage (Little et al., 2009; Sag et al., 2011). In mice chronically treated with DOX, heart dysfunction occurred at 15 weeks, which may be due to a depressed $\left[\mathrm{Ca}^{2+}\right]_{\mathrm{i}}$ transient (Llach et al., 2019). In another study, mechanical unloading helped increase functional sarcoplasmic reticulum $\mathrm{Ca}^{2+}$ ATPase and improved $\left[\mathrm{Ca}^{2+}\right]_{\mathrm{i}}$ handling and contractility in rats with DOX-induced cardiomyopathy (Takaseya et al., 2004). These findings implicate that alteration in $\mathrm{Ca}^{2+}$ handling in cardiac myocytes precedes clinical signs of heart dysfunction. A comparative short-term versus long-term exposure to DOX in rats helped delineate the sequence of calcium dysfunction when compared with other mechanisms. Findings from this study concluded that mtDNA depletion and its associated ETC impairment preceded calcium level disruption (Lebrecht et al., 2010). Nevertheless, targeting calcium dysfunction still remains a viable approach to treat DOX-mediated cardiotoxicity (Agustini et al., 2016; Gao et al., 2016).

Endothelin-1. Endothelin-1 (ET-1) is a potent vasoconstrictor peptide that stimulates a variety of cell types, including cardiomyocytes. ET-1 biologic effects include vasoconstriction, inflammation, cell division and proliferation, stimulation of free radical formation, and platelet activation (Böhm and Pernow, 2007). ET-1 has been implicated as an important factor in the development of vascular dysfunction, cardiovascular disease, and DIC, specifically at triggering a LV dysfunction (Bien et al., 2007). Its plasma concentrations increase upon DOX treatment in patients and in animal models of cardiomyopathy in both acute and chronic studies (Picard et al., 1998; Sayed-Ahmed et al., 2001; Suzuki and Miyauchi, 2001). A study by Schwebe et al. (2015) conducted on a murine DOX cardiotoxicity model also showed that the subunits $\mathrm{ET}_{\mathrm{A}}$ and $\mathrm{ET}_{\mathrm{B}}$ of $\mathrm{ET}-1$ receptors equally contribute to DIC and further presented a signal transduction pathways modulated by ET-1 antagonists. However, in primary neonatal rat cardiomyocytes, the ET-1 receptor, specifically through its $\mathrm{ET}_{\mathrm{A}}$ subunit, also showed a cytoprotective effect at rescuing DIC at an early phase through the upregulation of manganese superoxide dismutase (Suzuki and Miyauchi, 2001).

Topoisomerase-II. Another cellular target of DOX is topoisomerase-II, through which it induces single- and double-strand breaks in DNA (Tewey et al., 1984). Between the two isoforms of topoisomerases that exist, topoisomerase II $\beta$ is abundantly present in the mitochondria of adult cardiomyocytes. It forms a ternary cleavage complex with DOX and DNA, inducing DNA double-strand breaks and cell death (Capranico et al., 1992; Lyu et al., 2007). Furthermore, topoisomerase II $\beta$-specific role at mediating DIC has been demonstrated using the cardiomyocyte-specific topoisomerase II $\beta$ knockout mice (Zhang et al., 2012). Topoisomerase II $\beta$ role at mediating DIC is further confirmed by the protective effects of dexrazoxane, the only Food and Drug Administration (FDA)-approved drug to prevent DOXinduced HF (van Dalen et al., 2005; Deng et al., 2014). Findings from Deng et al. (2014) implied that dexrazoxane prevented double-strand breaks via topoisomerase II $\beta$ degradation rather than by iron chelation. This is the first in vivo report that presented transient depletion of topoisomerase II $\beta$ by dexrazoxane, confirming previous in vitro reports (Lyu et al., 2007; Yan et al., 2009).

With all of the above molecular mechanisms leading to DIC, its clinical use is limited. Although several mechanisms of DIC were identified, the relative contribution of each of those mechanisms is not yet completely understood. In an attempt to identify the pathways causing acute and chronic DIC, a systems pharmacological approach was used by de Oliveira and Niederer (2016). According to the simulations conducted using their systems-based model, ETC inhibition is considered to play a key role at mediating acute cardiotoxicity. This interpretation from a mathematical modeling perspective can also be corroborated by an earlier independent research finding from DOX-treated mice through pathway and biochemical analyses (Pointon et al., 2010), whereas direct mtDNA damage triggered by DOX is responsible for chronic cardiotoxicity at therapeutic doses, leading to further irreversible mitochondrial dysfunction. 


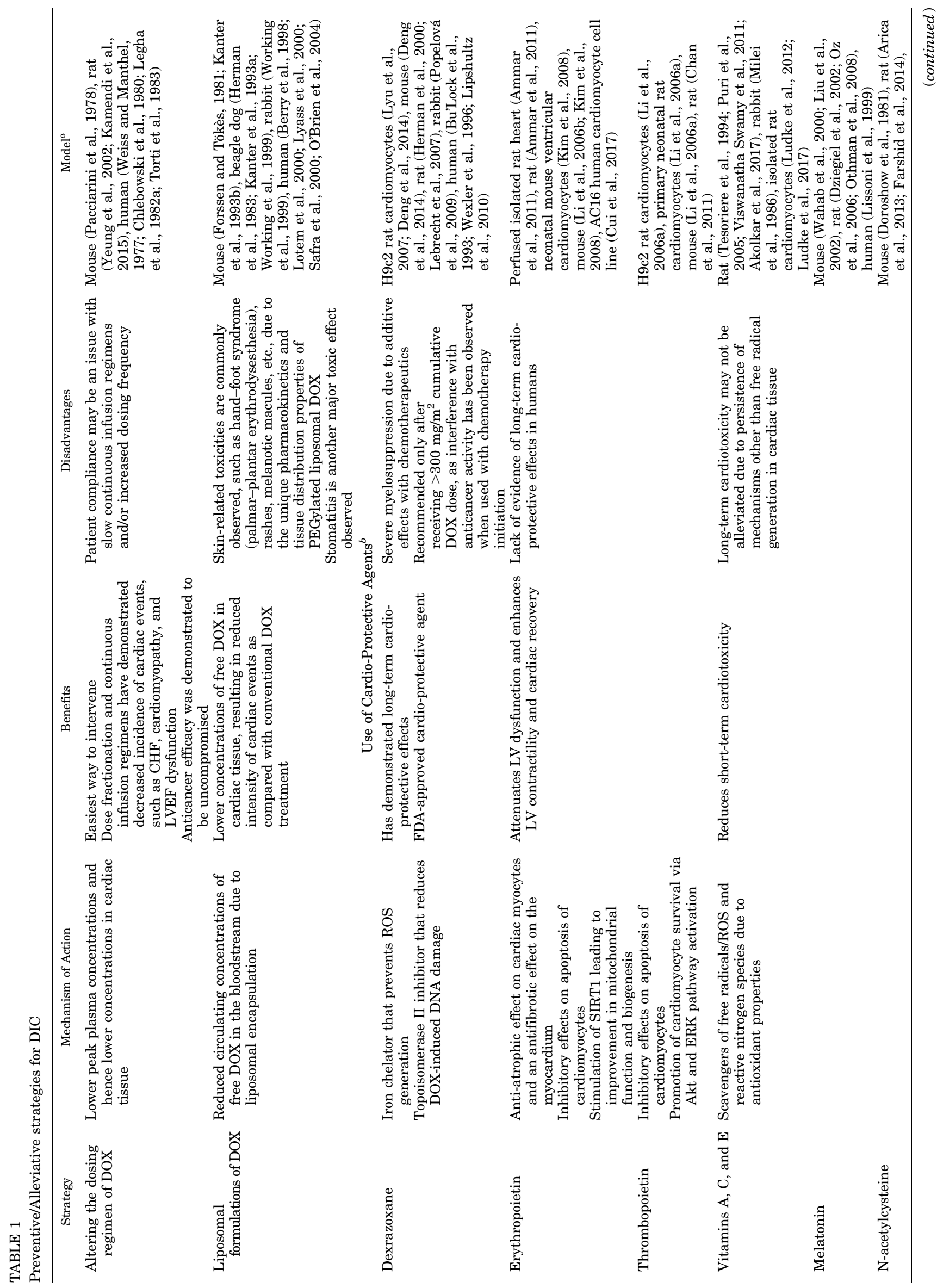

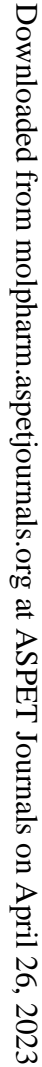




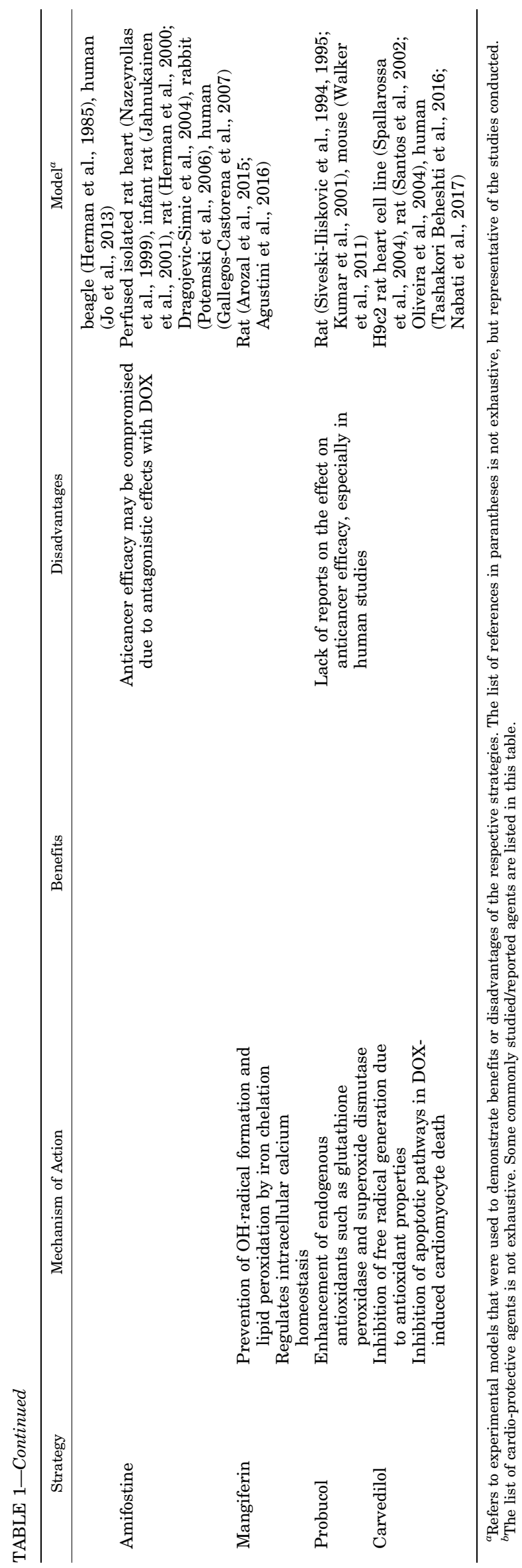

\section{Strategies for Prevention of DIC}

The primary strategies to prevent DIC are as follows: 1) drug administration via continuous infusion or liposome encapsulation and 2) simultaneous use of a cardio-protective agent, such as dexrazoxane along with DOX treatment. Other methods include coadministration of antioxidants or hematopoietic cytokines such as erythropoietin (EPO) and thrombopoietin (TPO). Table 1 summarizes the various strategies for the prevention and/or alleviation of DIC.

Altering Anthracycline Dosing Regimen. Following the evaluation of several dosing schedules in early clinical trials, slow continuous administration rather than large bolus doses of DOX is found to be safer from a cardiotoxicity point of view. Moreover, dose-fractionated weekly schedules of DOX have been found to significantly reduce cardiotoxic events, without compromising efficacy, as compared with the standard three-weekly dosing regimen (Lum et al., 1985). The mechanism is thought to be that, by maintaining lower peak plasma concentrations and hence lower concentrations of DOX in the heart, the intensity of exposure of cardiomyocytes to DOX is attenuated, thus leading to reduction in the occurrence of DIC (Pacciarini et al., 1978; Lum et al., 1985). Prolonged durations of DOX infusions for over 48-96 hours resulted in lower cardiotoxicity, while still demonstrating anticancer efficacy (Pacciarini et al., 1978). However, altering the administration time did not yield similar effects in adult patients versus pediatrics. For instance, continuous infusions over 48 hours were found to be a safer alternative in breast cancer women, whereas it did not render any cardioprotection to children with acute lymphoblastic leukemia treated with DOX (Legha et al., 1982b; Hortobagyi et al., 1989; Lipshultz et al., 2002).

Liposomal Formulation of DOX. Extensive research has been undertaken to examine modified formulations of DOX like utilizing liposomal encapsulation strategies to overcome its cardiotoxic effects, by several research groups (Tacar et al., 2013; Tahover et al., 2015; van den Hurk et al., 2015). Liposomal formulations allow for direct encapsulation of hydrophilic drug within the aqueous compartment or lipophilic drug incorporation into the lipid bilayer. Both polyethylene glycol (PEG)ylated and non-PEGylated forms of liposomal DOX formulations are commercially available, among which the PEGylated ones are the most frequently used within the United States (Allen and Cullis, 2013). Doxil is the FDA-approved PEGylated DOX liposomal formulation. It is indicated for patients with ovarian cancer, Kaposi's sarcoma, and multiple myeloma following failure of at least one prior chemotherapy (Barenholz, 2012). Liposomal formulations of DOX preferentially accumulate at the tumor site due to the enhanced permeability retention effect and elicit lower peak plasma concentrations of free DOX, thus diminishing cardiotoxic effects (Gabizon et al., 2003). Additionally, PEGylation of liposomes allows for prolonged circulation times in the bloodstream through evasion of uptake by the reticuloendothelial system, thus allowing retention of efficacy, while maintaining safety by encapsulation of free DOX (Gabizon et al., 2003; Torchilin, 2005). Moreover, a review of phase II and III clinical trials demonstrated that liposomal DOX formulations caused significantly lesser cardiotoxicity while retaining efficacy in breast cancer when used in combination with other chemotherapeutic agents, thus demonstrating 
potential to substitute liposomal DOX in place of conventional DOX as a safer option to treat cancers (Franco et al., 2018).

Antioxidants and Iron Chelators. Because enhanced oxidative stress is one of the major mechanisms of DIC, concomitant use of antioxidants can help in combating oxidative stress and its associated toxicity. Vitamin $\mathrm{C}$ was shown to be one such effective antioxidant in mitigating DOXinduced oxidative/nitrosative stress and apoptosis in cardiomyocytes and in rats (Akolkar et al., 2017). Resveratrol, a polyphenolic compound, was also found to have both prophylactic and therapeutic benefits in mitigating DOX-induced apoptosis and fibrosis in myocardium in DOX-treated rats (Shoukry et al., 2017). Bicalein, a bioflavonoid treatment, alleviated DIC by inhibition of myocardial oxidative stress and apoptosis in mice (Sahu et al., 2016). Mangiferin, a naturally occurring C-glucosylxanthone, is also found to exhibit protective effects in circumventing DIC in rats through its antioxidant capacity (Arozal et al., 2015). It exhibited greater cardio-protection compared with the common antioxidants such as vitamin $\mathrm{E}$ and silymarin, which can be attributed to its effect on other mechanisms like calcium regulation (Arozal et al., 2015; Agustini et al., 2016). Amifostine is another cardio-protective agent that is shown to alleviate DIC in perfused isolated rat hearts and in several preclinical animal models (Nazeyrollas et al., 1999; Dragojevic-Simic et al., 2004; Potemski et al., 2006). In vivo, amifostine gets dephosphorylated into WR-1065, an aminothiol, due to alkaline phosphatases present in the cellular membrane of small vessels. This aminothiol moiety is then thought to play an antioxidant role in normal tissue, rendering amifostine as a cytoprotectant (Smoluk et al., 1988). Despite its cardio-protective role demonstrated in preclinical studies, no conclusive results have been reported with studies in humans (GallegosCastorena et al., 2007). Other agents that have shown cardio-protection in response to DOX treatment include $\alpha$-linolenic acid, melatonin, $\mathrm{N}$-acetylcysteine, and sesame oil majorly through the activation of antioxidant pathways (Arica et al., 2013; Yu et al., 2013; Govender et al., 2014; Saleem et al., 2014).

In mice studies, probucol, an antihyperlipidemic drug, prevented DOX- and trastuzumab-mediated cardiotoxicity through its antioxidant effects (Walker et al., 2011). Carvedilol, a $\beta$-blocker, was shown to prevent DIC when tested in two independent randomized clinical trials conducted in female patients diagnosed with breast cancer, suggesting further investigation for validation of this agent as a suitable prophylactic agent (Tashakori Beheshti et al., 2016; Nabati et al., 2017). However, the exact mechanism of carvedilol cardioprotective effects is not fully known, where its potent antioxidant activity might be the major attribute. Other possible mechanisms include the restoration of SERCA2 promoter activity in myocytes and the blockade of downregulation of SERCA2 gene expression independent of its $\beta$-blocking activity. In addition, carvedilol antiapoptotic activity could be another contributing factor to its protection from DIC. Previous studies have shown the positive impact of carvedilol on cardiac mitochondria in vitro, ex vivo, and in vivo models. Particularly, carvedilol is sugested to act as an inhibitor of mitochondrial complex-I, which is known as a cause of DIC (Oliveira et al., 2005), and was demonstrated to be superior than propranolol against DIC, metoprolol for preventing from hydroxyl radical-induced cardiac contractility, and atenolol for preventing from DOX-induced cardiomyocyte apoptosis (Kalay et al., 2006). Considering the above findings, the cardio-protective effects of carvedilol appear to be related to its antioxidant and antiapoptotic properties rather than its $\beta$-blocking activity.

As discussed earlier, dexrazoxane is the only FDAapproved cardio-protective agent for prevent DIC. Although it was initially thought to act through chelating to intracellular iron, later it was discovered to exhibit its cardioprotective effect via its interaction with the topoisomerase II enzyme, thus preventing its binding to DOX (Lyu et al., 2007). A clinical trial conducted in children with acute lymphoblastic leukemia revealed the potential use of dexrazoxane at reducing the cardiac injury caused by DOX, as evident from its role on reducing the serum concentrations of troponin T (Lipshultz et al., 2004). Despite its proven efficacy in several clinical trials, the American Society of Clinical Oncology still recommends its use to only metastatic breast cancer patients receiving already a cumulative dose of DOX of at least $300 \mathrm{mg} / \mathrm{m}^{2}$ and who still need further treatment with DOX (Wexler et al., 1996; Swain et al., 1997; Lopez et al., 1998; Hensley et al., 2009; Lipshultz et al., 2010). It is also noteworthy to mention that for any other protective agent such as carvedilol to be approved by the FDA for the indication of cardio-protection from DIC, these agents should exhibit an equal or greater potency than dexrazoxane in a comparative clinical trial (Steiner and Hellmann, 2013).

Hematopoietic Cytokines. EPO plays a key role in the hematopoiesis and is commonly used for treating anemia (Perreault and Venters, 2018). EPO receptors are found to be expressed in several tissues, including the heart, brain, and skeletal muscle (Li et al., 2006b). EPO is proven efficacious in vitro as well as in vivo in mice by inhibiting apoptosis of cardiomyocytes and heart atrophy along with attenuation of left ventricular dysfunction in mice ( $\mathrm{Li}$ et al., 2006b). This cardio-protective effect of EPO was investigated in male Wistar rats and was shown to be associated with a decreased oxidative stress and apoptosis of cardiomyocytes (Ammar et al., 2011). A recent communication by Cui et al. (2017) linked the silent mating type information regulation 2 homo$\log 1$ to EPO-mediated cardio-protection against DICmediated through mitochondria dysfunction and toxicity. Similarly, TPO showed cardio-protective effects while examined on H9c2 cells, neonatal rat primary myocytes, and mouse models (Li et al., 2006a). Further investigations in rat models of acute and chronic DOX treatment demonstrated that TPO rescued heart function in both models, suggesting its effects to be mediated through modulating protein kinase B (AKT8 virus oncogene cellular homolog) and ERK pathways (Chan et al., 2011).

Treatment of CHF. CHF is often irreversible, but also treatable. This can be done in two ways: 1 ) relieve pressure of the heart, and 2) minimize causing factors of CHF in general. Usually, high blood pressure is reduced by using adrenocortical extract (ACE) inhibitors or angiotensin II receptor agonists. $\beta$-Blockers can also protect the heart from negative effects of the body's own stress hormones. Hence, the heart beats steadier and needs less oxygen. Another option for the treatment of CHF would be using an antimineralcorticoid like spironolactone, which reduces fluid retention, and thereby the high blood pressure, thus relieving the heart. 
TABLE 2

Summary of analytical techniques for measurement of DOX and doxorubicinol (DOXL) blood concentrations for TDM

\begin{tabular}{|c|c|c|}
\hline Method of Measurement & Measured Variable & Lower Limit of Quantification \\
\hline HPLC with fluorescence detection (Fogli et al., 1999) & $\begin{array}{l}\text { Daunorubicin, idarubicin, DOX, epirubicin, and } \\
\text { their 13-dihydro metabolites in human plasma } \\
\text { samples }\end{array}$ & $0.4 \mathrm{ng} / \mathrm{ml}$ \\
\hline $\begin{array}{l}\text { Liquid chromatography with tandem mass } \\
\text { spectrometry (Mazzucchelli et al., 2017) }\end{array}$ & $\begin{array}{l}\text { Concentration of DOX and DOXL in mouse plasma, } \\
\text { liver, kidney, tumor, urine }\end{array}$ & $\begin{array}{l}\text { Plasma: } 0.04 \text { (DOX); } 0.24 \text { (DOXL) } \\
\text { Liver: } 0.12 \text { (DOX); } 0.3 \text { (DOXL) } \\
\text { Kidney: } 0.43 \text { (DOX); } 0.32 \text { (DOXL) } \\
\text { Tumor: } 0.52 \text { (DOX); } 0.35 \text { (DOXL) } \\
\text { Urine: } 0.025 \text { (DOX); } 0.09 \text { (DOXL) }\end{array}$ \\
\hline Ultra-HPLC fluorescence (Pérez-Blanco et al., 2014) & Concentrations of DOX and DOXL in human plasma & $\begin{array}{l}\mathrm{DOX}=8 \mathrm{ng} / \mathrm{ml} \\
\text { DOXL }=3 \mathrm{ng} / \mathrm{ml}\end{array}$ \\
\hline $\begin{array}{l}\text { Radionuclide angiocardiography (Lu, 2005; Panjrath } \\
\text { and Jain, 2006) }\end{array}$ & Measurement of LVEF & Not applicable \\
\hline $\begin{array}{l}\text { Myocardial imaging using In-111-antimyosin } \\
\text { antibody (Hiroe et al., 1992) }\end{array}$ & $\begin{array}{l}\text { Uptake of In-111-antimyosin antibody in } \\
\text { myocardium by immunoscintigraphy in rats to } \\
\text { evaluate myocardial damage }\end{array}$ & Not applicable \\
\hline${ }^{123}$ I-MIBG scintigraphy (Lekakis et al., 1996) & $\begin{array}{l}\text { Cardiac }{ }^{123} \text { I-MIBG uptake to generate adrenergic } \\
\text { neuronal imaging in doxorubicin-treated patients }\end{array}$ & Not applicable \\
\hline $\begin{array}{l}\text { Scintigraphic detection of apoptosis } \\
\text { (Bennink et al., 2004) }\end{array}$ & $\begin{array}{l}\text { Assessment of early apoptosis using annexin } \mathrm{V} \\
\text { scintigraphy in rats }\end{array}$ & Not applicable \\
\hline
\end{tabular}

\section{Therapeutic Drug Monitoring of DIC}

A potential strategy that can be used for early detection and mitigation of DIC involves the therapeutic drug monitoring (TDM) of patients receiving DOX. Although traditionally TDM focused on measuring the drug concentrations in plasma to assess the pharmacokinetics of the drug for designing optimal dosing regimens, in later years it helped to determine the incidence of toxicity and adverse drug reactions (Kang and Lee, 2009). TDM often demands the utility of a combined strategy integrating pharmaceutical, pharmacokinetics, and pharmacodynamic analyses. Pharmacodynamic measures such as identifying cardiac biomarkers can aid at monitoring DIC (Pongprot et al., 2012). Table 2 gives an overview of different techniques that have been studied for the last 20 years and are being used presently. The aim of this review section is to take a closer look at these techniques to summarize the examined methods that are suitable for TDM of DOX with DIC as a dose-limiting toxicity.

As summarized in Table 2, various analytical techniques are available for TDM during DOX therapy, with varying degrees of sensitivity. Techniques such as measurements of DOX and doxorubicinol (DOX metabolite), LVEF, or endomyocardial biopsy are well established for TDM. Further investigations are warranted for some of the newer methods such as Indium-111 (In-111)-antimyosin imaging, 123labeled metaiodobenzylguanidine $\left({ }^{123} \mathrm{I}-\mathrm{MIBG}\right)$ scintigraphy, or TUNEL assay. Therefore, a combination of guidelines, as outlined in Fig. 2, and established monitoring methods is required to identify the risk for developing severe cardiac dysfunction in a timely manner, and thus, reduce mortality rates.

\section{Measurement of DOX and DOX Blood Concentrations}

Although DOX is proven cardiotoxic by itself, this serious side effect is amplified by its active metabolite, doxorubicinol (Olson et al., 1988). Despite several analytical highperformance liquid chromatography (HPLC) methods that are presently available for the quantification of both DOX and doxorubicinol in various biologic matrices such as human and rat plasma as well as mice tumors, methods to quantify the concentrations of both analytes in mouse tissues are lacking (Arnold et al., 2004; Liu et al., 2008c; Ibsen et al., 2013; Sottani et al., 2013). One of the primary needs for such type of methods is to capture the bio-distribution profile of nanoformulated DOX (e.g., liposomal DOX). DOX delivery via nano-formulations is one of the preventative techniques to successfully reduce this metabolism-dependent cardiotoxicity. Besides diminishing the cardiovascular side effect of DOX through the slow release of free drug from the nanocarrier, nano-formulations are meant to improve free drug availability, delivery, and accumulation at the tumor site (Mazzucchelli et al., 2017). Other metabolites of DOX such as DOX deoxyaglycone, DOX hydroxyaglycone, and doxorubicinol hydroxyaglycone are also suspected of increasing cardiac dysfunction by

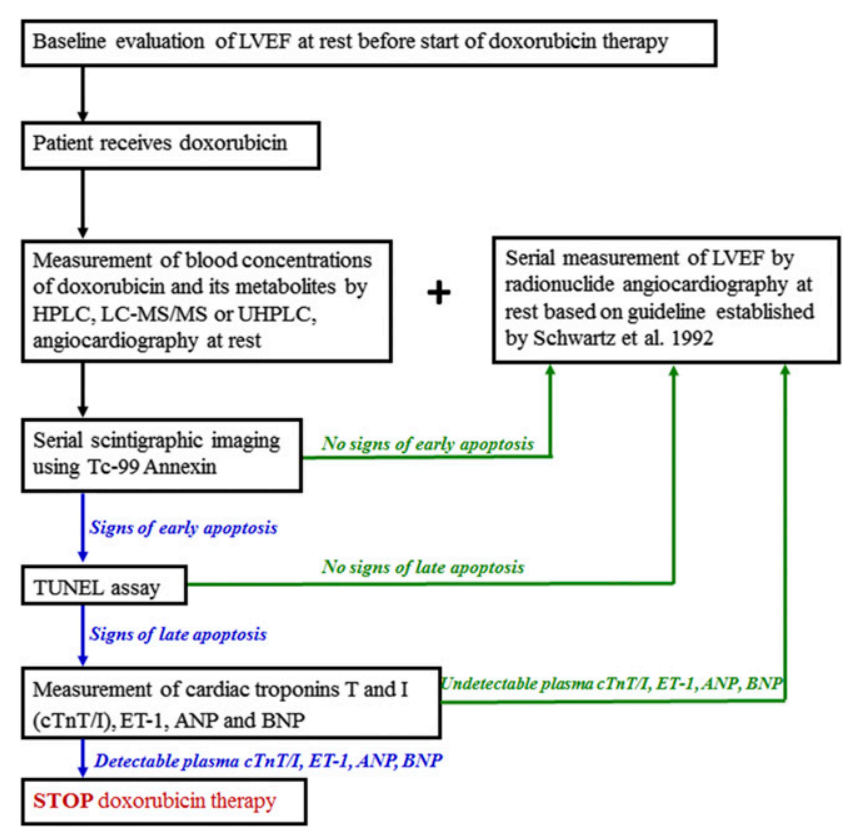

Fig. 2. Stepwise flowchart for the therapeutic drug monitoring of patients under DOX treatment of the prevention of DIC as a dose limiting toxicity. ANP, atrial natriuretic peptide; UHPLC, ultra-HPLC. 
inducing stress or perturbing iron homeostasis (Licata et al., 2000).

HPLC is one example for an established method to analyze the various metabolites mentioned above. Using HPLC, it is possible to tailor plasma concentrations of DOX and its various metabolites in patients undergoing DOX treatment. Furthermore, metabolites of different anthracyclines (daunorubicin, idarubicin, DOX, epirubicin) have been measured by HPLC coupled with fluorescence detection at 233, 254, and $480 \mathrm{~nm}$. This technique with a lower limit of quantification at $0.4 \mathrm{ng} / \mathrm{ml}$ and a signal-to-noise ratio of 3 is suitable for monitoring chemotherapeutic regimens of cancer patients (Fogli et al., 1999). A far easier, faster, and more costeffective analytical technique is liquid chromatography mass spectroscopy-coupled mass spectroscopy (LC-MS/MS), which allows quantification of DOX and doxorubicinol in different mice bio-matrices such as plasma, liver, kidney, or urine with a minimum quantity of samples. The different lower limit of quantification of tested matrices via LC-MS/MS for DOX is summarized in Table 2. In addition to HPLC and LC-MS/MS, ultra-HPLC fluorescence appears to be another simple, fast, and cost-effective technique to simultaneously measure large number of samples (about 15 samples/h) in broad concentration ranges for DOX as well as doxorubicinol. In comparison, LC-MS/MS detection is expensive and requires a long run time (Pérez-Blanco et al., 2014). However, a caveat to this technique is that it only enables quantification of the concentrations of DOX and its metabolites and does not quantify any specific early cardiac markers of DOX-induced heart injury.

\section{Measurement of DIC Biomarkers}

LVEF. Ejection fraction is the percent measurement of blood volume that the LV pumps during each contraction. In normal conditions, the LV ejects between $50 \%$ and $70 \%$ of its total blood capacity. A decrease in the LVEF of the heart is an early sign of cardiac dysfunction. It is presumed to be reversible; however, during anthracycline therapy it may progressively evolve into irreversible cardiomyopathy with LVEF $<40 \%$. Thus, LVEF is an important determinant for TDM of DOX-mediated cardiotoxicity (Jain, 2000). It can be measured by various techniques such as radionuclide angiocardiography, echocardiography, and Doppler echocardiography. LVEF analysis is easy to perform and provides reliable and reproducible measures of the LVEF. The latter has been used to detect and diagnose early cardiac alterations due to a variety of chemotherapeutics, including DOX (Lu, 2005; Panjrath and Jain, 2006). However, changes in LVEF during DOX therapy may not entirely be due to DOX, but to the presence of other confounding noncardiac conditions (Jain, 2000). Therefore, measurement of LVEF should not be used as the only method to monitor cardiac function of patients undergoing DOX treatment, but rather it should be combined with other techniques such as monitoring of plasma concentrations of DOX and its metabolites or measurement of the patient's angiocardiography at rest (Fig. 1).

In Vivo Imaging and Scintigraphic Techniques. Several in vivo imaging and scintigraphic techniques have been reported in the literature for the TDM of chemotherapyinduced HF (de Geus-Oei et al., 2011). These include the following: 1) In-111-antimyosin imaging, 2) ${ }^{123}$ I-MIBG scintigraphy, and 3) scintigraphic imaging using Tc-99 annexin
(Hiroe et al., 1992; Lekakis et al., 1996; Bennink et al., 2004). All three techniques use radioactive-labeled substances to identify different cardiac targets. In-111-antimyosin is a radioactive monoclonal antibody targeting intracellular myosin in the cardiac muscle. It was used as an immunoscintigraphic agent for the imaging of myocardial necrosis, hence, evaluating heart conditions related to diffuse myocardial cell injury (Hiroe et al., 1992). Uptake of In-111-antimyosin by the myocardium occurs only when the integrity of the sarcolemma is lost as a result of irreversible cardiac tissue damage (Hiroe et al., 1992). Although this immunoscintigraphic technique has provided insights into the molecular mechanisms of chemotherapy-induced cardiotoxicity, presently, it is no longer commercially available.

${ }^{123}$ I-MIBG scintigraphy is reported to be reproducible and sensitive and is able to detect abnormalities of myocardial adrenergic innervation prior to LVEF decreases. A few minutes after intravenous injection of ${ }^{123} \mathrm{I}-\mathrm{MIBG}$, the $\mathrm{LV}$ myocardium can be visualized. Its initial cardiac concentration (15 minutes after intravenous injection) depends on the cardiac blood flow and reflects both the extra- and intravesicular accumulation of ${ }^{123} \mathrm{I}-\mathrm{MIBG}$ in cardiac neurons. Generally, 4 hours after intravenous injection, this concentration reaches a constant value equivalent to the adrenergic neuron terminal concentration, used to examine specific cardiac neuron injury and loss of norepinephrine uptake function (Lekakis et al., 1996). In a study conducted on patients with various neoplasms and receiving DOX therapy, ${ }^{123}$ I-MIBG cardiac uptake was decreased in a DOX dosedependent manner, which demonstrates the cardiac adrenergic neurotoxic effect of DOX (Ono and Takahashi, 1994). Because the latter occurs much sooner than the decline of the ejection fraction, ${ }^{123} \mathrm{I}-\mathrm{MIBG}$ scintigraphy remains an attractive option for early detection of drug-related $\mathrm{HF}$.

${ }^{99 m}$ Tc-annexin scintigraphy has long been used to image apoptotic cardiomyocytes. Although, currently, this technique is no longer used as a diagnostic method for chemotherapyinduced cardiac impairment, its application has contributed to a better understanding of myocardial injury at the molecular and cellular levels. Apoptotic cardiomyocytes have been identified in cancer patients during anthracycline therapy (Lefrak et al., 1973; Unverferth et al., 1983; Goorin et al., 1990; Lipshultz et al., 1991). When cardiomyocytes start undergoing apoptosis, proteases and sphingomyelinases are activated. This leads to the phosphatidylserine molecules flipping to the extracellular layer of the cardiomyocyte membrane. At this stage, imaging of apoptotic cardiomyocytes is feasible using ${ }^{99 m}$ Tc-annexin V, which has a high affinity for the exposed phosphatidylserine molecules. These early phases of apoptosis precede the morphologic changes of cardiomyocytes' outer membrane layer by forming blebs and vesicles. Additionally, intracellular alterations also occur, such as breakdown of the cytoskeleton, cytoskeletal, reduction in the cytoplasm volume, condensation of the nuclear chromatin, and fragmentation of the DNA (Bennink et al., 2004). Several animal models of acute and chronic DOX-induced heart toxicity have been used and showed an elevated uptake by the myocardium of ${ }^{99 \mathrm{~m}} \mathrm{Tc}-$ annexin V. Animals with longer exposure to DOX showed higher DOX uptake. These results agreed well with findings on DOX cardiotoxicity examined using histopathology and immunohistochemistry techniques (Panjrath and Jain, 2006; Panjrath et al., 2007) and with other toxicity indices (Bennink 
et al., 2004). An alternative technique is the TUNEL assay, which allows the characterization of late-stage apoptosis by detecting DNA damage (Darzynkiewicz et al., 2008). This technique alone may not be entirely suitable for early TDM of DOX-induced cardiotoxicity given that only late apoptotic cells can be measured. Therefore, a combination of scintigraphic imaging using ${ }^{99 \mathrm{~m}} \mathrm{Tc}$-annexin $\mathrm{V}$ and TUNEL assay to detect both early and late apoptotic cells may be a useful option for TDM.

Specific Clinical Soluble Cardiac Biomarkers. Measurement of serum cardiac biomarkers such as cardiac troponins $\mathrm{T}$ and $\mathrm{I}$, atrial natriuretic peptide, and brain natriuretic peptide (BNP) should be considered for TDM of DOX treatment (Atas et al., 2015). Unlike scintigraphic and imaging techniques that have limited value in early detection of cardiotoxicity driven by chemotherapy, serum concentrations of these cardio-specific proteins released from damaged cardiomyocytes indicate early stages of myocardial injury. Initially, cardiac troponin $\mathrm{T}(\mathrm{c} \operatorname{Tn} \mathrm{T})$ was evaluated as a biomarker of DIC in a spontaneously hypertensive rat model (Herman et al., 1998). Results of this study demonstrated the potential for this early cardiac biomarker as a noninvasive evaluation method for clinical use in DOX therapy. Although cTnT was established as a suitable marker in several in vivo models, its application in children receiving DOX therapy is limited due to the lack of acute elevation of $c \operatorname{Tn} T$ following DOX therapy (Kismet et al., 2004; Koh et al., 2004; Clark et al., 2007).

DOX treatment also results in increase in the BNP levels along with cTnT, as demonstrated in a study in breast cancer patients (Advani et al., 2017). Recent evidence has established the superiority of two-dimensional speckle tracking echocardiography over conventional electrocardiography, coupled with cTnT levels, effectively leading to early detection of cardiotoxicity, thus improving TDM of DOX therapy (Wang et al., 2017). Secretion of natriuretic peptides such as BNP was associated with impaired LV diastolic function during DOX therapy in adult patients with non-Hodgkin's lymphoma (Nousiainen et al., 2002). Natriuretic peptide concentrations were also significantly elevated in the plasma of pediatric cancer patients with LVEF dysfunction; however, they are best correlated with systolic and not diastolic function in contrast to adult patients (Hayakawa et al., 2001). Despite the correlation between natriuretic peptide concentrations and reduced $\mathrm{LVEF}$, monitoring $\mathrm{LVEF}$ remains a clinical diagnostic and prognostic gold standard in DOX-induced $\mathrm{HF}$ (Daugaard et al., 2005).

In summary, several techniques have been introduced for TDM of patients treated with DOX and who are at risk of developing DIC. The use of only one of these techniques is not sufficient to reliably detect and/or confirm heart injury as a consequence of DOX therapy. Hence, a combination of these strategies in a step-wise manner as proposed in our flowchart (Fig. 2) is recommended. This approach will aid in the early diagnosis of cardiotoxicity caused by anthracycline-based therapy and will lead to faster clinical intervention and efficient management of this life-threatening adverse event. Finally, pilot studies in long-term survivors of childhood cancer suggest that comprehensive physical activity interventions may also be beneficial in avoiding delayed cardiotoxicity (Scully and Lipshultz, 2007). Furthermore, following these survivors for long-term in a comprehensive clinical program for identifying the late effects has also been demonstrated to be effective (Scully and Lipshultz, 2007).

\section{Discussion and Conclusions}

For most cancers, treatment with DOX remains an effective therapeutic option. However, the optimal use of DOX is restricted by its undesired cardiotoxicity and the limited possibilities for its prevention. As DOX is known to cause life-threatening cardiotoxicity in patients receiving cumulative doses of approximately $450-500 \mathrm{mg} / \mathrm{m}^{2}$, altering the dosing regimens of DOX is perhaps one of the most feasible strategies that can be implemented clinically to lessen or even overcome DIC. Some preclinical and clinical studies have demonstrated that modification of the dosing schedule of DOX by switching from bolus dosing or short-term infusion to continuous prolonged infusion, or by dose fractionation, leads to reduction in cardiotoxicity (Pacciarini et al., 1978; Legha et al., 1982b; Greene et al., 1983; Yeung et al., 2002). At present, there are no specific clinical practice guidelines for the management of DIC. Overall, available cardio-protective measures include a combination of natural antioxidants, $\beta$-blockers, ACE inhibitors, angiotensin receptor blockers, diuretics, nitrates, and hydralazine (Gianni et al., 2008), and heart transplantation for end-stage HF. Among those, ACE inhibitors and $\beta$-blockers showed best cardio-protective results in patients under DOX treatment (Kalay et al., 2006; Kaya et al., 2013; Cardinale et al., 2015). However, additional clinical studies are necessary to develop alternative pharmacological approaches and clinical practices for the diversified patient population treated with anthracycline-based chemotherapy.

Other cardio-protective measures aim at interfering with molecular and cellular mechanisms altered by DOX, such as the use of dexrazoxane, an iron-chelating agent. Not only is dexrazoxane the only drug with proven cardio-protective effects in cancer patients receiving anthracycline chemotherapy, but it is also the only cardio-protective drug approved by the Food and Drug Administration (FDA) in this population (Cvetković and Scott, 2005; Jones, 2008). Although dexrazoxane is a valuable option for prevention of DIC, a higher incidence of severe leukopenia (78\% vs. $68 \% ; P<0.01)$ is observed in patients receiving this drug. Hence, further investigations are required to identify agents that can mitigate the debilitating action of DOX on cardiomyocytes, along with an overall improved safety profile.

One of the key challenges that needs to be considered while selecting a cardio-protective agent for overcoming DIC is the parallel evaluation of the anticancer activity of that agent, such that oncological efficacy is not compromised. The key mechanisms of anticancer efficacy of DOX are as follows: 1) DNA damage caused by intercalation into DNA and disruption of topoisomerase II-mediated DNA repair, and 2) generation of ROS that causes damage to the cell membrane, proteins, and DNA, resulting ultimately in apoptosis (Thorn et al., 2011). Because these mechanisms largely overlap with those of DIC, there is a risk of loss of oncological efficacy, especially when cardio-protective agents acting through these mechanisms are used. For example, in the case of dexrazoxane, a retrospective analysis demonstrated that dosing with dexrazoxane after a cumulative dose of $>300 \mathrm{mg} / \mathrm{m}^{2}$ of DOX in cancer patients was not only cardio-protective, but also 
allowed retention of anticancer efficacy. This was in contrast to the treatment group that received dexrazoxane at the initiation of chemotherapy, wherein significant loss of anticancer efficacy was observed as compared with the group that received chemotherapy alone (Swain et al., 1997). Therefore, a potential strategy could include adjusting the timing of administration of cardio-protective agents such that oncological efficacy loss is minimized, while cardio-protective function is retained. Additionally, targeting pathways that are predominant in/specific to DIC, rather than DOX anticancer efficacy, could be another useful strategy to maintain the safety-efficacy balance with DOX-based therapy. For example, DOX is converted to its primary alcohol metabolite, doxorubicinol, via enzymatic conversion by aldo-keto reductase and carbonyl reductases 1 and 3 (Thorn et al., 2011). This metabolite plays a large role in causing cardiotoxicity via interference with iron and calcium homeostasis in cardiac tissue, and was demonstrated to be more potent than DOX itself (Olson et al., 1988). In contrast, in the same study, DOX retained superior potency over doxorubicinol in pancreatic adenocarcinoma cell lines in vitro, thus allowing dissociation of the anticancer effects from cardiotoxic effects of DOX. Therefore, inhibition of these metabolizing enzymes may possibly be a useful strategy to provide protection from doxorubicinol-mediated cardiotoxicity (Schaupp et al., 2015). However, further in vivo studies and detailed analyses are warranted to apply the above discussed strategies.

To date, TDM of DIC is a feasible option to detect the early signs of HF in patients treated with DOX, thereby preventing severe cardiac adverse events resulting from continued exposure to DOX. The identification and validation of the earliest detectable, sensitive, and reliable biomarkers for DIC is one of the most active fields of research in translational cancer research and cardiovascular medicine (Jones et al., 2011). With the advent of highly sensitive and automated analytical techniques for the measurement of drug and metabolite concentrations in blood, as well as the quantification of serum biomarkers discussed in this review, the combination of TDM along with early clinical symptoms of HF may be effectively and routinely implemented in the clinic to make DOX a safer chemotherapeutic option.

\section{Authorship Contributions}

Wrote or contributed to the writing of the manuscript: Wenningmann, Knapp, Ande, Vaidya, Ait-Oudhia.

\section{References}

Advani P, Hoyne J, Moreno-Aspita A, Dubin M, Brock S, Harlow C, Chumsri S, Suter $\mathrm{T}$, and Blackshear JL (2017) High-sensitivity troponin T and NT-proBNP kinetics in breast cancer chemotherapy. Chemotherapy 62:334-338.

Agustini FD, Arozal W, Louisa M, Siswanto S, Soetikno V, Nafrialdi N, and Suyatna

F (2016) Cardioprotection mechanism of mangiferin on doxorubicin-induced rats: focus on intracellular calcium regulation. Pharm Biol 54:1289-1297.

Akolkar G, da Silva Dias D, Ayyappan P, Bagchi AK, Jassal DS, Salemi VMC, Irigoyen MC, De Angelis K, and Singal PK (2017) Vitamin C mitigates oxidative/ nitrosative stress and inflammation in doxorubicin-induced cardiomyopathy. Am J Physiol Heart Circ Physiol 313:H795-H809.

Allen TM and Cullis PR (2013) Liposomal drug delivery systems: from concept to clinical applications. Adv Drug Deliv Rev 65:36-48.

Ammar HI, Saba S, Ammar RI, Elsayed LA, Ghaly WB, and Dhingra S (2011) Erythropoietin protects against doxorubicin-induced heart failure. Am J Physiol Heart Circ Physiol 301:H2413-H2421.

Arai M, Tomaru K, Takizawa T, Sekiguchi K, Yokoyama T, Suzuki T, and Nagai R (1998) Sarcoplasmic reticulum genes are selectively down-regulated in cardiomyopathy produced by doxorubicin in rabbits. J Mol Cell Cardiol 30:243-254.

Arica V, Demir İH, Tutanc M, Basarslan F, Arica S, Karcoiglu M, Öztürk H, and Nacar A (2013) N-acetylcysteine prevents doxorubucine-induced cardiotoxicity in rats. Hum Exp Toxicol 32:655-661.

Arnold RD, Slack JE, and Straubinger RM (2004) Quantification of Doxorubicin and metabolites in rat plasma and small volume tissue samples by liquid chromatography/electrospray tandem mass spectroscopy. J Chromatogr B Analyt Technol Biomed Life Sci 808:141-152.

Arola OJ, Saraste A, Pulkki K, Kallajoki M, Parvinen M, and Voipio-Pulkki LM (2000) Acute doxorubicin cardiotoxicity involves cardiomyocyte apoptosis. Cancer Res 60:1789-1792.

Arozal W, Suyatna FD, Juniantito V, Rosdiana DS, Amurugam S, Aulia R, Monayo ER, and Siswandi R (2015) The effects of mangiferin (mangifera indica L) in doxorubicin-induced cardiotoxicity in rats. Drug Res (Stuttg) 65:574-580.

Atas E, Kismet E, Kesik V, Karaoglu B, Aydemir G, Korkmazer N, Demirkaya E, Karslioglu Y, Yurttutan N, Unay B, et al. (2015) Cardiac troponin-I, brain natriuretic peptide and endothelin-1 levels in a rat model of doxorubicin-induced cardiac injury. J Cancer Res Ther 11:882-886.

Barenholz Y (2012) Doxil®--the first FDA-approved nano-drug: lessons learned. $J$ Control Release 160:117-134.

Bennink RJ, van den Hoff MJ, van Hemert FJ, de Bruin KM, Spijkerboer AL, Vanderheyden JL, Steinmetz N, and van Eck-Smit BL (2004) Annexin V imaging of acute doxorubicin cardiotoxicity (apoptosis) in rats. J Nucl Med 45:842-848.

Berry G, Billingham M, Alderman E, Richardson P, Torti F, Lum B, Patek A, and Martin FJ (1998) The use of cardiac biopsy to demonstrate reduced cardiotoxicity in AIDS Kaposi's sarcoma patients treated with pegylated liposomal doxorubicin. Ann Oncol 9:711-716.

Bien S, Riad A, Ritter CA, Gratz M, Olshausen F, Westermann D, Grube M, Krieg T, Ciecholewski S, Felix SB, et al. (2007) The endothelin receptor blocker bosentan inhibits doxorubicin-induced cardiomyopathy. Cancer Res 67:10428-10435.

Blum RH and Carter SK (1974) Adriamycin: a new anticancer drug with significant clinical activity. Ann Intern Med 80:249-259.

Böhm F and Pernow J (2007) The importance of endothelin-1 for vascular dysfunction in cardiovascular disease. Cardiovasc Res 76:8-18.

Bu'Lock FA, Gabriel HM, Oakhill A, Mott MG, and Martin RP (1993) Cardioprotection by ICRF187 against high dose anthracycline toxicity in children with malignant disease. Br Heart J 70:185-188.

Capranico G, Tinelli S, Austin CA, Fisher ML, and Zunino F (1992) Different patterns of gene expression of topoisomerase II isoforms in differentiated tissues during murine development. Biochim Biophys Acta 1132:43-48.

Cardinale D, Colombo A, Bacchiani G, Tedeschi I, Meroni CA, Veglia F, Civelli M, Lamantia G, Colombo N, Curigliano G, et al. (2015) Early detection of anthracycline cardiotoxicity and improvement with heart failure therapy. Circulation 131: 1981-1988.

Chan KY, Xiang P, Zhou L, Li K, Ng PC, Wang CC, Zhang L, Deng HY, Pong NH, Zhao H, et al. (2011) Thrombopoietin protects against doxorubicin-induced cardiomyopathy, improves cardiac function, and reversely alters specific signalling networks. Eur J Heart Fail 13:366-376.

Chlebowski RT, Paroly WS, Pugh RP, Hueser J, Jacobs EM, Pajak TF, and Bateman JR (1980) Adriamycin given as a weekly schedule without a loading course: clinically effective with reduced incidence of cardiotoxicity. Cancer Treat Rep 64:47-51.

Clark SJ, Pippon M, Hemsworth S, Newland P, and Pizer B (2007) Cardiac troponin $\mathrm{T}$ following anthracycline chemotherapy in children and adolescents. J Chemother 19:332-334.

Conte P, Gennari A, Guarneri V, Landucci E, Donati S, Salvadori B, Bengala C, Orlandini C, and Baldini E (2001) Epirubicin/taxane combinations in breast cancer: experience from several Italian trials. Oncology (Williston Park) 15 (Suppl 7): 21-23.

Cui L, Guo J, Zhang Q, Yin J, Li J, Zhou W, Zhang T, Yuan H, Zhao J, Zhang L, et al. (2017) Erythropoietin activates SIRT1 to protect human cardiomyocytes against doxorubicin-induced mitochondrial dysfunction and toxicity. Toxicol Lett $\mathbf{2 7 5}$ : $28-38$

Cvetković RS and Scott LJ (2005) Dexrazoxane: a review of its use for cardioprotection during anthracycline chemotherapy. Drugs 65:1005-1024.

Darzynkiewicz Z, Galkowski D, and Zhao H (2008) Analysis of apoptosis by cytometry using TUNEL assay. Methods 44:250-254.

Daugaard G, Lassen U, Bie P, Pedersen EB, Jensen KT, Abildgaard U, Hesse B, and Kjaer A (2005) Natriuretic peptides in the monitoring of anthracycline induced reduction in left ventricular ejection fraction. Eur J Heart Fail 7:87-93

de Geus-Oei LF, Mavinkurve-Groothuis AM, Bellersen L, Gotthardt M, Oyen WJ, Kapusta L, and van Laarhoven HW (2011) Scintigraphic techniques for early detection of cancer treatment-induced cardiotoxicity. J Nucl Med 52:560-571.

Delemasure S, Vergely C, Zeller M, Cottin Y, and Rochette L (2006) [Preventing the cardiotoxic effects of anthracyclins: from basic concepts to clinical data]. Ann Cardiol Angeiol (Paris) 55:104-112.

Deng S, Yan T, Jendrny C, Nemecek A, Vincetic M, Gödtel-Armbrust U, and Wojnowski L (2014) Dexrazoxane may prevent doxorubicin-induced DNA damage via depleting both topoisomerase II isoforms. BMC Cancer 14:842.

de Oliveira BL and Niederer S (2016) A biophysical systems approach to identifying the pathways of acute and chronic doxorubicin mitochondrial cardiotoxicity. PLOS Comput Biol 12:e1005214.

Doroshow JH, Locker GY, Ifrim I, and Myers CE (1981) Prevention of doxorubicin cardiac toxicity in the mouse by $\mathrm{N}$-acetylcysteine. J Clin Invest 68:1053-1064.

Dragojevic-Simic VM, Dobric SL, Bokonjic DR, Vucinic ZM, Sinovec SM, Jacevic VM and Dogovic NP (2004) Amifostine protection against doxorubicin cardiotoxicity in rats. Anticancer Drugs 15:169-178.

Dziegiel P, Jethon Z, Suder E, Sopel M, Rabczyński J, Surowiak P, and Zabel M (2002) Role of exogenous melatonin in reducing the cardiotoxic effect of daunorubicin and doxorubicin in the rat. Exp Toxicol Pathol 53:433-439.

Farshid AA, Tamaddonfard E, Simaee N, Mansouri S, Najafi S, Asri-Rezaee S, and Alavi $\mathrm{H}$ (2014) Effects of histidine and N-acetylcysteine on doxorubicininduced cardiomyopathy in rats. Cardiovasc Toxicol 14:153-161.

Fogli S, Danesi R, Innocenti F, Di Paolo A, Bocci G, Barbara C, and Del Tacca M (1999) An improved HPLC method for therapeutic drug monitoring of daunorubicin, idarubicin, doxorubicin, epirubicin, and their 13-dihydro metabolites in human plasma. Ther Drug Monit 21:367-375. 
Forssen EA and Tökès ZA (1981) Use of anionic liposomes for the reduction of chronic doxorubicin-induced cardiotoxicity. Proc Natl Acad Sci USA 78:1873-1877.

Franco YL, Vaidya TR, and Ait-Oudhia S (2018) Anticancer and cardio-protective effects of liposomal doxorubicin in the treatment of breast cancer. Breast Cancer (Dove Med Press) 10:131-141.

Gabizon A, Shmeeda H, and Barenholz Y (2003) Pharmacokinetics of pegylated liposomal Doxorubicin: review of animal and human studies. Clin Pharmacokinet 42:419-436.

Gallegos-Castorena S, Martínez-Avalos A, Mohar-Betancourt A, Guerrero-Avendaño G, Zapata-Tarrés M, and Medina-Sansón A (2007) Toxicity prevention with amifostine in pediatric osteosarcoma patients treated with cisplatin and doxorubicin. Pediatr Hematol Oncol 24:403-408.

Gao J, Chen T, Zhao D, Zheng J, and Liu Z (2016) Ginkgolide B exerts cardioprotective properties against doxorubicin-induced cardiotoxicity by regulating reactive oxygen species, Akt and calcium signaling pathways in vitro and in vivo. PLoS One 11:e0168219.

Gianni L, Herman EH, Lipshultz SE, Minotti G, Sarvazyan N, and Sawyer DB (2008) Anthracycline cardiotoxicity: from bench to bedside. J Clin Oncol 26:3777-3784.

Goorin AM, Chauvenet AR, Perez-Atayde AR, Cruz J, McKone R, and Lipshultz SE (1990) Initial congestive heart failure, six to ten years after doxorubicin chemotherapy for childhood cancer. J Pediatr 116:144-147.

Goormaghtigh E, Huart P, Brasseur R, and Ruysschaert JM (1986) Mechanism of inhibition of mitochondrial enzymatic complex I-III by adriamycin derivatives. Biochim Biophys Acta 861:83-94.

Goormaghtigh E, Huart P, Praet M, Brasseur R, and Ruysschaert JM (1990) Structure of the adriamycin-cardiolipin complex: role in mitochondrial toxicity. Biophys Chem 35:247-257.

Goormaghtigh E, Pollakis G, and Ruysschaert JM (1983) Mitochondrial membrane modifications induced by adriamycin-mediated electron transport. Biochem Pharmacol 32:889-893.

Govender J, Loos B, Marais E, and Engelbrecht AM (2014) Mitochondrial catastrophe during doxorubicin-induced cardiotoxicity: a review of the protective role of melatonin. J Pineal Res 57:367-380.

Greene RF, Collins JM, Jenkins JF, Speyer JL, and Myers CE (1983) Plasma pharmacokinetics of adriamycin and adriamycinol: implications for the design of in vitro experiments and treatment protocols. Cancer Res 43:3417-3421.

Hayakawa H, Komada Y, Hirayama M, Hori H, Ito M, and Sakurai M (2001) Plasma levels of natriuretic peptides in relation to doxorubicin-induced cardiotoxicity and cardiac function in children with cancer. Med Pediatr Oncol 37:4-9.

Hensley ML, Hagerty KL, Kewalramani T, Green DM, Meropol NJ, Wasserman TH Cohen GI, Emami B, Gradishar WJ, Mitchell RB, et al. (2009) American Society of Clinical Oncology 2008 clinical practice guideline update: use of chemotherapy and radiation therapy protectants. $J$ Clin Oncol 27:127-145.

Herman EH, Ferrans VJ, Myers CE, and Van Vleet JF (1985) Comparison of the effectiveness of (+/-)-1,2-bis(3,5-dioxopiperazinyl-1-yl)propane (ICRF-187) and $\mathrm{N}$-acetylcysteine in preventing chronic doxorubicin cardiotoxicity in beagles Cancer Res 45:276-281.

Herman EH, Lipshultz SE, Rifai N, Zhang J, Papoian T, Yu ZX, Takeda K, and Ferrans VJ (1998) Use of cardiac troponin T levels as an indicator of doxorubicin-induced cardiotoxicity. Cancer Res 58:195-197.

Herman EH, Rahman A, Ferrans VJ, Vick JA, and Schein PS (1983) Prevention of chronic doxorubicin cardiotoxicity in beagles by liposomal encapsulation. Cancer Res 43:5427-5432.

Herman EH, Zhang J, Chadwick DP, and Ferrans VJ (2000) Comparison of the protective effects of amifostine and dexrazoxane against the toxicity of doxorubicin in spontaneously hypertensive rats. Cancer Chemother Pharmacol 45:329-334.

Hiroe M, Ohta Y, Fujita N, Nagata M, Toyozaki T, Kusakabe K, Sekiguchi M, and Marumo F (1992) Myocardial uptake of 111In monoclonal antimyosin Fab in detecting doxorubicin cardiotoxicity in rats: morphological and hemodynamic findings. Circulation 86:1965-1972.

Hortobagyi GN, Frye D, Buzdar AU, Ewer MS, Fraschini G, Hug V, Ames F, Montague E, Carrasco CH, Mackay B, et al. (1989) Decreased cardiac toxicity of doxorubicin administered by continuous intravenous infusion in combination chemotherapy for metastatic breast carcinoma. Cancer 63:37-45.

Ibsen S, Su Y, Norton J, Zahavy E, Hayashi T, Adams S, Wrasidlo W, and Esener S (2013) Extraction protocol and mass spectrometry method for quantification of doxorubicin released locally from prodrugs in tumor tissue. J Mass Spectrom 48: $768-773$.

Jahnukainen K, Jahnukainen T, Salmi TT, Svechnikov K, Eksborg S, and Söder O (2001) Amifostine protects against early but not late toxic effects of doxorubicin in infant rats. Cancer Res 61:6423-6427.

Jain D (2000) Cardiotoxicity of doxorubicin and other anthracycline derivatives. $J$ Nucl Cardiol 7:53-62.

Jo SH, Kim LS, Kim SA, Kim HS, Han SJ, Park WJ, and Choi YJ (2013) Evaluation of short-term use of $\mathrm{N}$-acetylcysteine as a strategy for prevention of anthracyclineinduced cardiomyopathy: EPOCH trial - a prospective randomized study. Korean Circ J 43:174-181.

Jones DS, Cambrosio A, and Mogoutov A (2011) Detection and characterization of translational research in cancer and cardiovascular medicine. J Transl Med 9:57.

Jones RL (2008) Utility of dexrazoxane for the reduction of anthracycline-induced cardiotoxicity. Expert Rev Cardiovasc Ther 6:1311-1317.

Kalay N, Basar E, Ozdogru I, Er O, Cetinkaya Y, Dogan A, Inanc T, Oguzhan A Eryol NK, Topsakal R, et al. (2006) Protective effects of carvedilol against anthracycline-induced cardiomyopathy. $J$ Am Coll Cardiol 48:2258-2262.

Kalivendi SV, Konorev EA, Cunningham S, Vanamala SK, Kaji EH, Joseph J, and Kalyanaraman B (2005) Doxorubicin activates nuclear factor of activated T-lymphocytes and Fas ligand transcription: role of mitochondrial reactive oxygen species and calcium. Biochem $J$ 389:527-539.

Kamendi H, Zhou Y, Crosby M, Keirstead N, Snow D, Bentley P, Patel N, Barthlow H, Luo W, Dragan Y, et al. (2015) Doxorubicin: comparison between 3-h continuous and bolus intravenous administration paradigms on cardio-renal axis, mitochondrial sphingolipids and pathology. Toxicol Appl Pharmacol 289:560-572.

Kang JS and Lee MH (2009) Overview of therapeutic drug monitoring. Korean $J$ Intern Med (Korean Assoc Intern Med) 24:1-10.

Kanter PM, Bullard GA, Ginsberg RA, Pilkiewicz FG, Mayer LD, Cullis PR, and Pavelic ZP (1993a) Comparison of the cardiotoxic effects of liposomal doxorubicin (TLC D-99) versus free doxorubicin in beagle dogs. In Vivo 7:17-26.

Kanter PM, Bullard GA, Pilkiewicz FG, Mayer LD, Cullis PR, and Pavelic ZP (1993b) Preclinical toxicology study of liposome encapsulated doxorubicin (TLC D-99): comparison with doxorubicin and empty liposomes in mice and dogs. In Vivo 7 $85-95$.

Kaya MG, Ozkan M, Gunebakmaz O, Akkaya H, Kaya EG, Akpek M, Kalay N, Dikilitas M, Yarlioglues M, Karaca H, et al. (2013) Protective effects of nebivolo against anthracycline-induced cardiomyopathy: a randomized control study. Int $J$ Cardiol 167:2306-2310.

Kayser K, Kayser G, Andre S, Altiner M, and Gabius H (1999) Evaluation of histochemical anthracyclin binding as potential prognostic parameter in small cell lung cancer. Oncol Rep 6:1153-1157.

Kim KH, Oudit GY, and Backx PH (2008) Erythropoietin protects against doxorubicin-induced cardiomyopathy via a phosphatidylinositol 3-kinasedependent pathway. J Pharmacol Exp Ther 324:160-169.

Kismet E, Varan A, Ayabakan C, Alehan D, Portakal O, and Büyükpamukçu M (2004) Serum troponin T levels and echocardiographic evaluation in children treated with doxorubicin. Pediatr Blood Cancer 42:220-224.

Koh E, Nakamura T, and Takahashi H (2004) Troponin-T and brain natriuretic peptide as predictors for adriamycin-induced cardiomyopathy in rats. Circ $J \mathbf{6 8}$ : 163-167.

Kumar D, Kirshenbaum LA, Li T, Danelisen I, and Singal PK (2001) Apoptosis in adriamycin cardiomyopathy and its modulation by probucol. Antioxid Redox Signal 3:135-145.

Lebrecht D, Geist A, Ketelsen UP, Haberstroh J, Setzer B, and Walker UA (2007) Dexrazoxane prevents doxorubicin-induced long-term cardiotoxicity and protects myocardial mitochondria from genetic and functional lesions in rats. $\mathrm{Br} J \mathrm{Phar}$ macol 151:771-778.

Lebrecht D, Kirschner J, Geist A, Haberstroh J, and Walker UA (2010) Respiratory chain deficiency precedes the disrupted calcium homeostasis in chronic doxorubicin cardiomyopathy. Cardiovasc Pathol 19:e167-e174.

Lefrak EA, Pitha J, Rosenheim S, and Gottlieb JA (1973) A clinicopathologic analysis of adriamycin cardiotoxicity. Cancer 32:302-314.

Legha SS, Benjamin RS, Mackay B, Ewer M, Wallace S, Valdivieso M, Rasmussen SL, Blumenschein GR, and Freireich EJ (1982a) Reduction of doxorubicin cardiotoxicity by prolonged continuous intravenous infusion. Ann Intern Med 96:133-139.

Legha SS, Benjamin RS, Mackay B, Yap HY, Wallace S, Ewer M, Blumenschein GR, and Freireich EJ (1982b) Adriamycin therapy by continuous intravenous infusion in patients with metastatic breast cancer. Cancer 49:1762-1766.

Lekakis J, Prassopoulos V, Athanassiadis P, Kostamis P, and Moulopoulos S (1996) Doxorubicin-induced cardiac neurotoxicity: study with iodine 123-labeled metaiodobenzylguanidine scintigraphy. $J$ Nucl Cardiol 3:37-41.

Li K, Sung RY, Huang WZ, Yang M, Pong NH, Lee SM, Chan WY, Zhao H, To MY, Fok TF, et al. (2006a) Thrombopoietin protects against in vitro and in vivo car diotoxicity induced by doxorubicin. Circulation 113:2211-2220.

Li L, Takemura G, Li Y, Miyata S, Esaki M, Okada H, Kanamori H, Khai NC, Maruyama R, Ogino A, et al. (2006b) Preventive effect of erythropoietin on cardiac dysfunction in doxorubicin-induced cardiomyopathy. Circulation 113:535-543.

Licata S, Saponiero A, Mordente A, and Minotti G (2000) Doxorubicin metabolism and toxicity in human myocardium: role of cytoplasmic deglycosidation and carbonyl reduction. Chem Res Toxicol 13:414-420.

Lipshultz SE, Colan SD, Gelber RD, Perez-Atayde AR, Sallan SE, and Sanders SP (1991) Late cardiac effects of doxorubicin therapy for acute lymphoblastic leukemia in childhood. $N$ Engl J Med 324:808-815.

Lipshultz SE, Giantris AL, Lipsitz SR, Kimball Dalton V, Asselin BL, Barr RD, Clavell LA, Hurwitz CA, Moghrabi A, Samson Y, et al. (2002) Doxorubicin administration by continuous infusion is not cardioprotective: the Dana-Farber 91-01 acute lymphoblastic leukemia protocol. J Clin Oncol 20:1677-1682.

Lipshultz SE, Rifai N, Dalton VM, Levy DE, Silverman LB, Lipsitz SR, Colan SD, Asselin BL, Barr RD, Clavell LA, et al. (2004) The effect of dexrazoxane on myocardial injury in doxorubicin-treated children with acute lymphoblastic leukemia. N Engl J Med 351:145-153.

Lipshultz SE, Scully RE, Lipsitz SR, Sallan SE, Silverman LB, Miller TL, Barry EV, Asselin BL, Athale U, Clavell LA et al. (2010) Assessment of dexrazoxane as a cardioprotectant in doxorubicin-treated children with high-risk acute lymphoblastic leukaemia: long-term follow-up of a prospective, randomised, multicentre trial. Lancet Oncol 11:950-961.

Lissoni P, Barni S, Mandalà M, Ardizzoia A, Paolorossi F, Vaghi M, Longarini R, Malugani F, and Tancini G (1999) Decreased toxicity and increased efficacy of cancer chemotherapy using the pineal hormone melatonin in metastatic solid tumour patients with poor clinical status. Eur J Cancer 35:1688-1692.

Little GH, Saw A, Bai Y, Dow J, Marjoram P, Simkhovich B, Leeka J, Kedes L, Kloner RA, and Poizat C (2009) Critical role of nuclear calcium/calmodulindependent protein kinase IIdeltaB in cardiomyocyte survival in cardiomyopathy. $J$ Biol Chem 284:24857-24868.

Liu J, Mao W, Ding B, and Liang CS (2008a) ERKs/p53 signal transduction pathway is involved in doxorubicin-induced apoptosis in H9c2 cells and cardiomyocytes. Am $J$ Physiol Heart Circ Physiol 295:H1956-H1965.

Liu TJ, Yeh YC, Ting CT, Lee WL, Wang LC, Lee HW, Wang KY, Lai HC, and Lai HC (2008b) Ginkgo biloba extract 761 reduces doxorubicin-induced apoptotic damage in rat hearts and neonatal cardiomyocytes. Cardiovasc Res 80:227-235.

Liu X, Chen Z, Chua CC, Ma YS, Youngberg GA, Hamdy R, and Chua BH (2002) Melatonin as an effective protector against doxorubicin-induced cardiotoxicity. Am J Physiol Heart Circ Physiol 283:H254-H263. 
Liu Y, Yang Y, Liu X, and Jiang T (2008c) Quantification of pegylated liposomal doxorubicin and doxorubicinol in rat plasma by liquid chromatography/electrospray tandem mass spectroscopy: application to preclinical pharmacokinetic studies. Talanta 74:887-895.

Llach A, Mazevet M, Mateo P, Villejouvert O, Ridoux A, Rucker-Martin C, Ribeiro M, Fischmeister R, Crozatier B, Benitah JP, et al. (2019) Progression of excitationcontraction coupling defects in doxorubicin cardiotoxicity. J Mol Cell Cardiol 126 129-139.

Lopez M, Vici P, Di Lauro K, Conti F, Paoletti G, Ferraironi A, Sciuto R, Giannarelli D, and Maini CL (1998) Randomized prospective clinical trial of high-dose epirubicin and dexrazoxane in patients with advanced breast cancer and soft tissue sarcomas. J Clin Oncol 16:86-92.

Lotem M, Hubert A, Lyass O, Goldenhersh MA, Ingber A, Peretz T, and Gabizon A (2000) Skin toxic effects of polyethylene glycol-coated liposomal doxorubicin. Arch Dermatol 136:1475-1480.

$\mathrm{Lu} \mathrm{P}$ (2005) Monitoring cardiac function in patients receiving doxorubicin. Semin Nucl Med 35:197-201.

Ludke A, Akolkar G, Ayyappan P, Sharma AK, and Singal PK (2017) Time course of changes in oxidative stress and stress-induced proteins in cardiomyocytes exposed to doxorubicin and prevention by vitamin C. PLoS One 12:e179452.

Ludke A, Sharma AK, Bagchi AK, and Singal PK (2012) Subcellular basis of vitamin $\mathrm{C}$ protection against doxorubicin-induced changes in rat cardiomyocytes. Mol Cell Biochem 360:215-224.

Lum BL, Svec JM, and Torti FM (1985) Doxorubicin: alteration of dose scheduling as a means of reducing cardiotoxicity. Drug Intell Clin Pharm 19:259-264.

Lyass O, Uziely B, Ben-Yosef R, Tzemach D, Heshing NI, Lotem M, Brufman G, and Gabizon A (2000) Correlation of toxicity with pharmacokinetics of pegylated liposomal doxorubicin (Doxil) in metastatic breast carcinoma. Cancer 89 1037-1047.

Lyu YL, Kerrigan JE, Lin CP, Azarova AM, Tsai YC, Ban Y, and Liu LF (2007) Topoisomerase IIbeta mediated DNA double-strand breaks: implications in doxorubicin cardiotoxicity and prevention by dexrazoxane. Cancer Res 67:8839-8846.

Marcillat O, Zhang Y, and Davies KJ (1989) Oxidative and non-oxidative mechanisms in the inactivation of cardiac mitochondrial electron transport chain components by doxorubicin. Biochem J 259:181-189.

Matsuoka T, Nomizu T, Yabuta T, Katagata N, Watanabe F, Yamaki Y, Tsuchiya A, and Takenoshita S (2000) [Chemotherapy with mitoxantrone for the treatment of recurrent breast cancer]. Gan To Kagaku Ryoho 27:1051-1055.

Mazzucchelli S, Ravelli A, Gigli F, Minoli M, Corsi F, Ciuffreda P, and Ottria R (2017) LC-MS/MS method development for quantification of doxorubicin and its metabolite 13-hydroxy doxorubicin in mice biological matrices: application to a pharmaco-delivery study. Biomed Chromatogr 31:1-10.

Milei J, Boveris A, Llesuy S, Molina HA, Storino R, Ortega D, and Milei SE (1986) Amelioration of adriamycin-induced cardiotoxicity in rabbits by prenylamine and vitamins A and E. Am Heart $J$ 111:95-102.

Minotti G, Menna P, Salvatorelli E, Cairo G, and Gianni L (2004) Anthracyclines: molecular advances and pharmacologic developments in antitumor activity and cardiotoxicity. Pharmacol Rev 56:185-229.

Mitry MA and Edwards JG (2016) Doxorubicin induced heart failure: phenotype and molecular mechanisms. Int J Cardiol Heart Vasc 10:17-24.

Mizutani H, Tada-Oikawa S, Hiraku Y, Kojima M, and Kawanishi S (2005) Mechanism of apoptosis induced by doxorubicin through the generation of hydrogen peroxide. Life Sci 76:1439-1453.

Moreira AC, Branco AF, Sampaio SF, Cunha-Oliveira T, Martins TR, Holy J, Oliveira PJ, and Sardão VA (2014) Mitochondrial apoptosis-inducing factor is involved in doxorubicin-induced toxicity on H9c2 cardiomyoblasts. Biochim Biophys Acta 1842 : $2468-2478$.

Nabati M, Janbabai G, Baghyari S, Esmaili K, and Yazdani J (2017) Cardioprotective effects of carvedilol in inhibiting doxorubicin-induced cardiotoxicity. $J$ Cardiovasc Pharmacol 69:279-285.

Nakamura T, Ueda Y, Juan Y, Katsuda S, Takahashi H, and Koh E (2000) Fasmediated apoptosis in adriamycin-induced cardiomyopathy in rats: in vivo study. Circulation 102:572-578

Nazeyrollas P, Prévost A, Baccard N, Manot L, Devillier P, and Millart H (1999) Effects of amifostine on perfused isolated rat heart and on acute doxorubicininduced cardiotoxicity. Cancer Chemother Pharmacol 43:227-232.

Nicolay K, Fok JJ, Voorhout W, Post JA, and de Kruijff B (1986) Cytofluorescence detection of adriamycin-mitochondria interactions in isolated, perfused rat heart. Biochim Biophys Acta 887:35-41.

Nousiainen T, Vanninen E, Jantunen E, Puustinen J, Remes J, Rantala A, Vuolteenaho $\mathrm{O}$, and Hartikainen $\mathrm{J}$ (2002) Natriuretic peptides during the development of doxorubicin-induced left ventricular diastolic dysfunction. J Intern Med $\mathbf{2 5 1}$ $228-234$.

O'Brien ME, Wigler N, Inbar M, Rosso R, Grischke E, Santoro A, Catane R, Kieback DG, Tomczak P, Ackland SP, et al; CAELYX Breast Cancer Study Group (2004) Reduced cardiotoxicity and comparable efficacy in a phase III trial of pegylated liposomal doxorubicin HCl (CAELYX/Doxil) versus conventional doxorubicin for first-line treatment of metastatic breast cancer. Ann Oncol 15:440-449.

Octavia Y, Tocchetti CG, Gabrielson KL, Janssens S, Crijns HJ, and Moens AL (2012) Doxorubicin-induced cardiomyopathy: from molecular mechanisms to therapeutic strategies. J Mol Cell Cardiol 52:1213-1225.

Oliveira PJ, Bjork JA, Santos MS, Leino RL, Froberg MK, Moreno AJ, and Wallace KB (2004) Carvedilol-mediated antioxidant protection against doxorubicin-induced cardiac mitochondrial toxicity. Toxicol Appl Pharmacol 200:159-168.

Oliveira PJ, Gonçalves L, Monteiro P, Providencia LA, and Moreno AJ (2005) Are the antioxidant properties of carvedilol important for the protection of cardiac mitochondria? Curr Vasc Pharmacol 3:147-158.

Olson RD, Mushlin PS, Brenner DE, Fleischer S, Cusack BJ, Chang BK, and Boucek RJ Jr (1988) Doxorubicin cardiotoxicity may be caused by its metabolite, doxorubicinol. Proc Natl Acad Sci USA 85:3585-3589.
Ono M and Takahashi T (1994) [123I-MIBG scintigraphy in cardiotoxicity related to antineoplastic agents]. Kaku Igaku 31:451-458.

Othman AI, El-Missiry MA, Amer MA, and Arafa M (2008) Melatonin controls oxidative stress and modulates iron, ferritin, and transferrin levels in adriamycin treated rats. Life Sci 83:563-568.

Oz E, Erbaș D, Sürücü HS, and Düzgün E (2006) Prevention of doxorubicin-induced cardiotoxicity by melatonin. Mol Cell Biochem 282:31-37.

Pacciarini MA, Barbieri B, Colombo T, Broggini M, Garattini S, and Donelli MG (1978) Distribution and antitumor activity of adriamycin given in a high-dose and a repeated low-dose schedule to mice. Cancer Treat Rep 62:791-800.

Panjrath GS and Jain D (2006) Monitoring chemotherapy-induced cardiotoxicity: role of cardiac nuclear imaging. $J$ Nucl Cardiol 13:415-426.

Panjrath GS, Patel V, Valdiviezo CI, Narula N, Narula J, and Jain D (2007) Potentiation of Doxorubicin cardiotoxicity by iron loading in a rodent model. J Am Coll Cardiol 49:2457-2464.

Pendlebury A, DeBernardo R, and Rose PG (2017) Long-term use of pegylated liposomal doxorubicin to a cumulative dose of $4600 \mathrm{mg} / \mathrm{m} 2$ in recurrent ovarian cancer. Anticancer Drugs 28:815-817.

Pérez-Blanco JS, Fernández de Gatta MdelM, Hernández-Rivas JM, García Sánchez MJ, Sayalero Marinero ML, and González López F (2014) Validation and clinical evaluation of a UHPLC method with fluorescence detector for plasma quantification of doxorubicin and doxorubicinol in haematological patients. $J$ Chromatogr $B$ Analyt Technol Biomed Life Sci 955-956:93-97.

Perreault AA and Venters BJ (2018) Integrative view on how erythropoietin signaling controls transcription patterns in erythroid cells. Curr Opin Hematol 25: 189-195.

Picard P, Smith PJ, Monge JC, Rouleau JL, Nguyen QT, Calderone A, and Stewart DJ (1998) Coordinated upregulation of the cardiac endothelin system in a rat model of heart failure. J Cardiovasc Pharmacol 31 (Suppl 1):S294-S297.

Pointon AV, Walker TM, Phillips KM, Luo J, Riley J, Zhang SD, Parry JD, Lyon JJ, Marczylo EL, and Gant TW (2010) Doxorubicin in vivo rapidly alters expression and translation of myocardial electron transport chain genes, leads to ATP loss and caspase 3 activation. PLoS One 5:e12733.

Pongprot Y, Sittiwangkul R, Charoenkwan P, and Silvilairat S (2012) Use of cardiac markers for monitoring of doxorubixin-induced cardiotoxicity in children with cancer. J Pediatr Hematol Oncol 34:589-595.

Popelová O, Sterba M, Hasková P, Simůnek T, Hroch M, Guncová I, Nachtigal $\mathrm{P}$, Adamcová M, Gersl V, and Mazurová Y (2009) Dexrazoxane-afforded protection against chronic anthracycline cardiotoxicity in vivo: effective rescue of cardiomyocytes from apoptotic cell death. Br J Cancer 101:792-802.

Potemski P, Polakowski P, Wiktorowska-Owczarek AK, Owczarek J, Płuzańska A and Orszulak-Michalak D (2006) Amifostine improves hemodynamic parameters in doxorubicin-pretreated rabbits. Pharmacol Rep 58:966-972.

Priya LB, Baskaran R, Huang CY, and Padma VV (2017) Neferine ameliorates cardiomyoblast apoptosis induced by doxorubicin: possible role in modulating NADPH oxidase/ROS-mediated $\mathrm{NF}_{\kappa} \mathrm{B}$ redox signaling cascade. Sci Rep 7:12283.

Puri A, Maulik SK, Ray R, and Bhatnagar V (2005) Electrocardiographic and biochemical evidence for the cardioprotective effect of vitamin $\mathrm{E}$ in doxorubicininduced acute cardiotoxicity in rats. Eur J Pediatr Surg 15:387-391.

Qiu AF, Miao ZL, Ge GK, Wang CB, Bian J, Ma HY, and Xu Q (2017) [Response and prognosis of neoadjuvant dose-dense or standard schedule chemotherapy with anthracyclines and taxanes for Luminal B breast cancer]. Zhonghua Yi Xue Za Zhi 97:3466-3470.

Renu K, v G A, P B TP, and Arunachalam S (2018) Molecular mechanism of doxorubicin-induced cardiomyopathy - an update. Eur $J$ Pharmacol 818: 241-253.

Rochette L, Guenancia C, Gudjoncik A, Hachet O, Zeller M, Cottin Y, and Vergely C (2015) Anthracyclines/trastuzumab: new aspects of cardiotoxicity and molecular mechanisms. Trends Pharmacol Sci 36:326-348.

Safra T, Muggia F, Jeffers S, Tsao-Wei DD, Groshen S, Lyass O, Henderson R, Berry G, and Gabizon A (2000) Pegylated liposomal doxorubicin (doxil): reduced clinical cardiotoxicity in patients reaching or exceeding cumulative doses of $500 \mathrm{mg} / \mathrm{m} 2$ Ann Oncol 11:1029-1033.

Sag CM, Köhler AC, Anderson ME, Backs J, and Maier LS (2011) CaMKII-dependent SR Ca leak contributes to doxorubicin-induced impaired Ca handling in isolated cardiac myocytes. J Mol Cell Cardiol 51:749-759.

Sahu BD, Kumar JM, Kuncha M, Borkar RM, Srinivas R, and Sistla R (2016) Baicalein alleviates doxorubicin-induced cardiotoxicity via suppression of myocardial oxidative stress and apoptosis in mice. Life Sci 144:8-18.

Saleem MT, Chetty MC, and Kavimani S (2014) Antioxidants and tumor necrosis factor alpha-inhibiting activity of sesame oil against doxorubicin-induced cardiotoxicity. Ther Adv Cardiovasc Dis 8:4-11.

Santos DL, Moreno AJ, Leino RL, Froberg MK, and Wallace KB (2002) Carvedilo protects against doxorubicin-induced mitochondrial cardiomyopathy. Toxicol Appl Pharmacol 185:218-227.

Sayed-Ahmed MM, Khattab MM, Gad MZ, and Osman AM (2001) Increased plasma endothelin-1 and cardiac nitric oxide during doxorubicin-induced cardiomyopathy. Pharmacol Toxicol 89:140-144.

Schaupp CM, White CC, Merrill GF, and Kavanagh TJ (2015) Metabolism of doxorubicin to the cardiotoxic metabolite doxorubicinol is increased in a mouse model of chronic glutathione deficiency: a potential role for carbonyl reductase 3. Chem Biol Interact 234:154-161.

Schlame M, Rua D, and Greenberg ML (2000) The biosynthesis and functional role of cardiolipin. Prog Lipid Res 39:257-288.

Schwebe M, Ameling S, Hammer E, Monzel JV, Bonitz K, Budde S, Schult K, Oswald S, Scheuch E, Grube M, et al. (2015) Protective effects of endothelin receptor A and B inhibitors against doxorubicin-induced cardiomyopathy. Biochem Pharmacol 94 109-129.

Scully RE and Lipshultz SE (2007) Anthracycline cardiotoxicity in long-term survivors of childhood cancer. Cardiovasc Toxicol 7:122-128. 
Shah CM (2009) Amrubicin: a synthetic anthracyclin analogue in the treatment of extensive stage small cell lung cancer. Recent Patents Anticancer Drug Discov 4: 241-245.

Shoukry HS, Ammar HI, Rashed LA, Zikri MB, Shamaa AA, Abou Elfadl SG, Rub EA, Saravanan S, and Dhingra S (2017) Prophylactic supplementation of resveratrol is more effective than its therapeutic use against doxorubicin induced cardiotoxicity. PLoS One 12:e181535.

Siveski-Iliskovic N, Hill M, Chow DA, and Singal PK (1995) Probucol protects against adriamycin cardiomyopathy without interfering with its antitumor effect. Circulation 91:10-15.

Siveski-Iliskovic N, Kaul N, and Singal PK (1994) Probucol promotes endogenous antioxidants and provides protection against adriamycin-induced cardiomyopathy in rats. Circulation 89:2829-2835.

Smoluk GD, Fahey RC, Calabro-Jones PM, Aguilera JA, and Ward JF (1988) Radioprotection of cells in culture by WR-2721 and derivatives: form of the drug responsible for protection. Cancer Res 48:3641-3647.

Sottani C, Poggi G, Melchiorre F, Montagna B, and Minoia C (2013) Simultaneous measurement of doxorubicin and reduced metabolite doxorubicinol by UHPLC-MS/ MS in human plasma of HCC patients treated with TACE. $J$ Chromatogr B Analyt Technol Biomed Life Sci 915-916:71-78.

Spallarossa P, Garibaldi S, Altieri P, Fabbi P, Manca V, Nasti S, Rossettin P, Ghigliotti G, Ballestrero A, Patrone F, et al. (2004) Carvedilol prevents doxorubicininduced free radical release and apoptosis in cardiomyocytes in vitro. J Mol Cell Cardiol 37:837-846.

Steiner R and Hellmann K (2013) Dexrazoxane prevention of anthracycline cardiomyopathy. J Clin Oncol 31:1379.

Suzuki T and Miyauchi T (2001) A novel pharmacological action of ET-1 to prevent the cytotoxicity of doxorubicin in cardiomyocytes. Am J Physiol Regul Integr Comp Physiol 280:R1399-R1406.

Swain SM, Whaley FS, Gerber MC, Ewer MS, Bianchine JR, and Gams RA (1997) Delayed administration of dexrazoxane provides cardioprotection for patients with advanced breast cancer treated with doxorubicin-containing therapy. J Clin Oncol 15:1333-1340

Tacar O, Sriamornsak P, and Dass CR (2013) Doxorubicin: an update on anticancer molecular action, toxicity and novel drug delivery systems. J Pharm Pharmacol 65: 157-170.

Tahover E, Patil YP, and Gabizon AA (2015) Emerging delivery systems to reduce doxorubicin cardiotoxicity and improve therapeutic index: focus on liposomes. Anticancer Drugs 26:241-258.

Takaseya T, Ishimatsu M, Tayama E, Nishi A, Akasu T, and Aoyagi S (2004) Mechanical unloading improves intracellular $\mathrm{Ca} 2+$ regulation in rats with doxorubicin-induced cardiomyopathy. J Am Coll Cardiol 44:2239-2246.

Takemura G and Fujiwara H (2007) Doxorubicin-induced cardiomyopathy from the cardiotoxic mechanisms to management. Prog Cardiovasc Dis 49:330-352.

Tashakori Beheshti A, Mostafavi Toroghi H, Hosseini G, Zarifian A, Homaei Shandiz F, and Fazlinezhad A (2016) Carvedilol administration can prevent doxorubicininduced cardiotoxicity: a double-blind randomized trial. Cardiology 134:47-53.

Tesoriere L, Ciaccio M, Valenza M, Bongiorno A, Maresi E, Albiero R, and Livrea MA (1994) Effect of vitamin A administration on resistance of rat heart against doxorubicin-induced cardiotoxicity and lethality. J Pharmacol Exp Ther $\mathbf{2 6 9}$ $430-436$.

Tewey KM, Rowe TC, Yang L, Halligan BD, and Liu LF (1984) Adriamycin-induced DNA damage mediated by mammalian DNA topoisomerase II. Science 226 466-468.

Thorn CF, Oshiro C, Marsh S, Hernandez-Boussard T, McLeod H, Klein TE, and Altman RB (2011) Doxorubicin pathways: pharmacodynamics and adverse effects. Pharmacogenet Genomics 21:440-446.

Tokarska-Schlattner M, Zaugg M, Zuppinger C, Wallimann T, and Schlattner U (2006) New insights into doxorubicin-induced cardiotoxicity: the critical role of cellular energetics. $J$ Mol Cell Cardiol 41:389-405.

Torchilin VP (2005) Recent advances with liposomes as pharmaceutical carriers. Nat Rev Drug Discov 4:145-160.

Torti FM, Bristow MR, Howes AE, Aston D, Stockdale FE, Carter SK, Kohler M, Brown BW Jr, and Billingham ME (1983) Reduced cardiotoxicity of doxorubicin delivered on a weekly schedule: assessment by endomyocardial biopsy. Ann Intern Med 99:745-749.
Unverferth BJ, Magorien RD, Balcerzak SP, Leier CV, and Unverferth DV (1983) Early changes in human myocardial nuclei after doxorubicin Cancer 52.215-221. van Dalen EC, Caron HN, Dickinson HO, and Kremer LC (2005) Cardioprotective interventions for cancer patients receiving anthracyclines. Cochrane Database Syst Rev (1):CD003917.

van den Hurk C, Breed W, and Dercksen W (2015) Nonpegylated liposomal doxorubicin: reduction in cardiotoxicity, although still severe alopecia. Anticancer Drugs 26:687.

Vejpongsa P and Yeh ET (2014) Prevention of anthracycline-induced cardiotoxicity: challenges and opportunities. J Am Coll Cardiol 64:938-945.

Viswanatha Swamy AH, Wangikar U, Koti BC, Thippeswamy AH, Ronad PM, and Manjula DV (2011) Cardioprotective effect of ascorbic acid on doxorubicininduced myocardial toxicity in rats. Indian J Pharmacol 43:507-511.

Volkova M and Russell R III (2011) Anthracycline cardiotoxicity: prevalence, pathogenesis and treatment. Curr Cardiol Rev 7:214-220.

Wahab MH, Akoul ES, and Abdel-Aziz AA (2000) Modulatory effects of melatonin and vitamin $\mathrm{E}$ on doxorubicin-induced cardiotoxicity in Ehrlich ascites carcinomabearing mice. Tumori 86:157-162.

Walker JR, Sharma A, Lytwyn M, Bohonis S, Thliveris J, Singal PK, and Jassal DS (2011) The cardioprotective role of probucol against anthracycline and trastuzumabmediated cardiotoxicity. J Am Soc Echocardiogr 24:699-705

Wallace KB (2007) Adriamycin-induced interference with cardiac mitochondrial calcium homeostasis. Cardiovasc Toxicol 7:101-107.

Wang W, Kang Y, Shu XH, Shen XD, and He B (2017) [Early detection of the cardiotoxicity induced by chemotherapy drug through two-dimensional speckle tracking echocardiography combined with high-sensitive cardiac troponin T]. Zhonghua Zhong Liu Za Zhi 39:835-840.

Wei Y, Gao L, Wang L, Shi L, Wei E, Zhou B, Zhou L, and Ge B (2017) Polydopamine and peptide decorated doxorubicin-loaded mesoporous silica nanoparticles as a targeted drug delivery system for bladder cancer therapy. Drug Deliv 24:681-691.

Weinstein DM, Mihm MJ, and Bauer JA (2000) Cardiac peroxynitrite formation and left ventricular dysfunction following doxorubicin treatment in mice. J Pharmacol Exp Ther 294:396-401.

Weiss AJ and Manthel RW (1977) Experience with the use of adriamycin in combination with other anticancer agents using a weekly schedule, with particular reference to lack of cardiac toxicity. Cancer 40:2046-2052

Wexler LH, Andrich MP, Venzon D, Berg SL, Weaver-McClure L, Chen CC, Dilsizian V, Avila N, Jarosinski P, Balis FM, et al. (1996) Randomized trial of the cardioprotective agent ICRF-187 in pediatric sarcoma patients treated with doxorubicin. J Clin Oncol 14:362-372.

Working PK, Newman MS, Sullivan T, and Yarrington J (1999) Reduction of the cardiotoxicity of doxorubicin in rabbits and dogs by encapsulation in longcirculating, pegylated liposomes. J Pharmacol Exp Ther 289:1128-1133.

Yan T, Deng S, Metzger A, Gödtel-Armbrust U, Porter AC, and Wojnowski L (2009) Topoisomerase IIalpha-dependent and -independent apoptotic effects of dexrazoxane and doxorubicin. Mol Cancer Ther 8:1075-1085.

Yeung TK, Chakrabarti K, Wilding D, and Hopewell JW (2002) Modification of doxorubicin-induced cardiotoxicity: manipulation of the dosage schedule. Hum Exp Toxicol 21:607-614.

Yu X, Cui L, Zhang Z, Zhao Q, and Li S (2013) $\alpha$-Linolenic acid attenuates doxorubicin-induced cardiotoxicity in rats through suppression of oxidative stress and apoptosis. Acta Biochim Biophys Sin (Shanghai) 45:817-826.

Zhang DX, Ma DY, Yao ZQ, Fu CY, Shi YX, Wang QL, and Tang QQ (2016) ERK1/2/ p53 and NF-кB dependent-PUMA activation involves in doxorubicin-induced cardiomyocyte apoptosis. Eur Rev Med Pharmacol Sci 20:2435-2442.

Zhang S, Liu X, Bawa-Khalfe T, Lu LS, Lyu YL, Liu LF, and Yeh ET (2012) Identification of the molecular basis of doxorubicin-induced cardiotoxicity. Nat Med 18:1639-1642.

Zhao L and Zhang B (2017) Doxorubicin induces cardiotoxicity through upregulation of death receptors mediated apoptosis in cardiomyocytes. Sci Rep 7:44735.

Address correspondence to: Dr. Sihem Ait-Oudhia, Center for Pharmacometrics and Systems Pharmacology, Department of Pharmaceutics, College of Pharmacy, University of Florida, 6550 Sanger Road, Office \#469, Orlando, FL 32827. E-mail: sihem.bihorel@cop.ufl.edu 